\title{
A new phenomenological criterion for pellet-cladding interaction rupture
}

\author{
B. Michel *, J. Sercombe, G. Thouvenin \\ CEA Cadarache DEC/SESC, 13108 St. Paul Lez Durance, France
}

\begin{abstract}
This study is concerned with structural integrity assessment of Pressure Water Reactor's (PWR) fuel rods under pellet-cladding interaction (PCI) loading condition. An important experimental and research cooperative program between EDF, AREVA-NP and the Atomic Energy Commission CEA is achieved in order to get a better understanding of the mechanisms possibly leading to PCI failure, as well as to qualify a PCI resistant rod design. The objectives of this work are: first, to improve the understanding of the pellet mechanical properties impact on cladding local loading with 3D simulations results, and second, to propose a new phenomenological rupture criterion for a better assessment of the failure risk.

In this study fuel behaviour modelling under nominal and transient loading conditions is achieved with a multi-dimensional simulation tool called ALCYONE, included in the new fuel software PLEIADES currently co-developed by the CEA and EDF. Cladding loading due to mechanical interaction during power transient stage is first analysed through pellet-cladding interfacial stresses computed in the 3D simulation. Then, a $2 \mathrm{D}$ model is proposed in order to establish a correlation between interfacial loading and stress concentration in the cladding. In order to assess the failure risk under PCI a phenomenological criterion based on the membrane circumferential stress in the cladding and shear stresses at pellet-cladding interface is proposed. To compute the shear loading at pellet-cladding interface a new parameter (called $W_{r \theta}$ ) is introduced. Based on $3 \mathrm{D}$ calculations of PCI, it is shown in this paper that pellet fracture properties can have a significant effect on PCI loading.
\end{abstract}

(C) 2008 Elsevier B.V. All rights reserved.

\section{Introduction}

Pellet-cladding interaction (PCI) failures, discovered in the early 1970s, can be avoided in Pressurized Water Reactors (PWRs) thanks to optimized plant operational procedures and fuel management schemes. Research and development programs are however still undertaken worldwide on this subject in order to improve the understanding of the mechanisms possibly leading to PCI failure, as well as to qualify a PCI resistant rod design. In this purpose simulation tools for PWR rods subjected to "Class 2 " transient loading conditions has been developed at the CEA.

Modelling PCI in PWRs requires accounting for various physical phenomena in the fuel pellet and the cladding on a wide range of scales. PCI modelling at the CEA was previously achieved through two different simulation code called METEOR (Struzik et al., 1997) and TOUTATIS (Brochard et al., 1997). The former is based on a continuum 1D axisymetric description of the radial dimension of the fuel element, associated to a discrete axial decomposition of the fuel rod. This 1D

\footnotetext{
* Corresponding author. Tel.: +334422534 73; fax: +33442 252949 .

E-mail address: bruno.michel@cea.fr (B. Michel).
}

code was developed from the TRANSURANUS fuel software (Lassmann and Blank, 1988), with the main objective to couple complex models needed for every aspects of fuel behaviour modelling. This kind of code enables to have an assessment of global geometrical changes and of fission products behaviour under irradiation up to high burn-up levels. A finite element mechanical model (Garcia et al., 2002), based on an axisymetric stress distribution, has been developed for the METEOR code. However, local assessment of the cladding loading in the case of PCI ruptures need a more detailed model based on a 2D or 3D description of the fuel component. For this purpose, at the same time, the 3D fuel code TOUTATIS (Brochard et al., 1997) has been developed with the CAST3M finite element code to take into detailed aspects of the thermo-mechanical behaviour under irradiation. Some developments of the 3D model concerning the thermo-mechanical coupling, friction aspects at pellet-cladding interface and pellet fragmentation has been presented in Ref. Bentejac (2004).

Recently, in order to enables the use of the most advanced models for chemical-physics and thermo-mechanical aspects, according the knowledge coming from the METEOR and the TOUTATIS codes, a new multi-dimensional PWR fuel code called ALCYONE (Thouvening et al., 2006) has been developed 
in the PLEIADES (Plancq, 2004) fuel software environment. Despite this large number of simulation tools PCI rupture assessment has still been difficult due to non-linear multi-physics aspects leading to complex competition phenomena. It is for instance very difficult to have a rupture criterion independent of the fuel or cladding material properties, or to have a critical value of this criterion identified on a laboratory specimen, or to explain cladding crack location for the whole experimental database. Then, the objective of this study is to contribute to a better understanding of PCI rupture mechanisms, for this we will focus on thermo-mechanical loading transmitted at pellet-cladding interface.

In a first part, the 3D fuel behaviour simulation module of ALCYONE used in this study will be detailed. In the second part, the strain-stress field at pellet-cladding interface will be analysed through the 3D simulation and its impact on local strain-stress field in the cladding will be discussed with 2D simulation results. In a third part a phenomenological criterion for rupture assessment under PCI will be proposed, and pellet fracture properties impact on PCI loading will be discussed.

\section{Fuel behaviour modelling}

\subsection{Multi-physic problem}

The main phenomena involved in fuel behaviour modelling are detailed on illustration of Fig. 1. These phenomena can be separated into two kinds: on one side, nuclear power deposition and structural material changes due to fission products, and on the other side power evacuation and mechanical stresses and strains induced by local volume variations. Formers are mainly linked to mechanisms at an atomistic scale (densification and solid swelling process, gaseous fission products behaviour, etc.), when the latter are more relevant of larger scale commonly used for integrity assessment of structure under thermo-mechanical loading. The numerical scheme used in the $3 \mathrm{D}$ approach is based on a weak-coupling formulation between thermal, physic of irradiation and mechanical problems as presented in Fig. 2. On the latter we can see that gaseous swelling is not included in the convergence loop, but is introduced as pre-computed input data coming from the 1D computation code called METEOR (Struzik et al., 1997).

\subsection{Thermo-mechanical behaviour under irradiation}

\subsubsection{Pellet}

Uncompressible viscoplastic behaviour under irradiation is taken into account in the pellet (1), where fission density rate leads to: an induced creep effect (second term of Eq. (1)) with a low level of activation energy $\left(Q_{i c}\right)$, and an enhancement of the thermal creep (parameter $\alpha$ ). Material evolutions due to irradiation are furthermore introduced in the model by the dependency of material parameters on the burn-up level and porosity of the fuel pellet. As an example, the thermal conductivity is calculated according to a modified version of Lucuta's law, originally given in Ref. Lucuta et al. (1996) Concerning the mechanical properties of the fuel pellet, the impact of porosity on the elastic and creep parameters is taken into account. In this respect, a poro-viscoplastic compressible formulation for creep has been developed (Monerie and Gatt, 2006). Fuel cracking during irradiation and its coupling to viscoplastic behaviour is taken into account through a non-unified formulation (Contesti, 1989). Constitutive equation of the fuel cracking model and its validation are detailed in Ref. Michel et al. (2007).

$$
\begin{aligned}
& \frac{\mathrm{d} \varepsilon_{\text {creep }}}{\mathrm{d} t}=\max \left[A_{i}\left(p, D_{\mathrm{G}}\right)\left(J_{2}(\overline{\bar{\sigma}})\right)^{n_{i}} \mathrm{e}^{-\frac{Q_{i}}{R T}}\right]\left(1+\alpha \frac{\mathrm{d} F}{\mathrm{~d} t}\right) \\
& +B\left(J_{2}(\overline{\bar{\sigma}})\right) \frac{\mathrm{d} F}{\mathrm{~d} t} \mathrm{e}^{-\frac{Q_{i c}}{R T}}
\end{aligned}
$$

In Eq. (1) $\mathrm{d} \varepsilon_{\text {creep }} / \mathrm{d} t$ is the total creep strain rate, $J_{2}(\overline{\bar{\sigma}})$ the second invariant of the deviatoric stress tensor, $t$ the time, $T$ the temperature, $p$ the porosity, $D_{\mathrm{G}}$ the fuel grain size, $\left(A_{i}, n_{i}, Q_{i}, B, \alpha, Q_{i c}\right)$ are material parameters, subscript $i$ is equal to 1 and 2 for each thermal creep stage, $\mathrm{d} F / \mathrm{d} t$ is the fission density rate and $R$ is the universal gas constant.

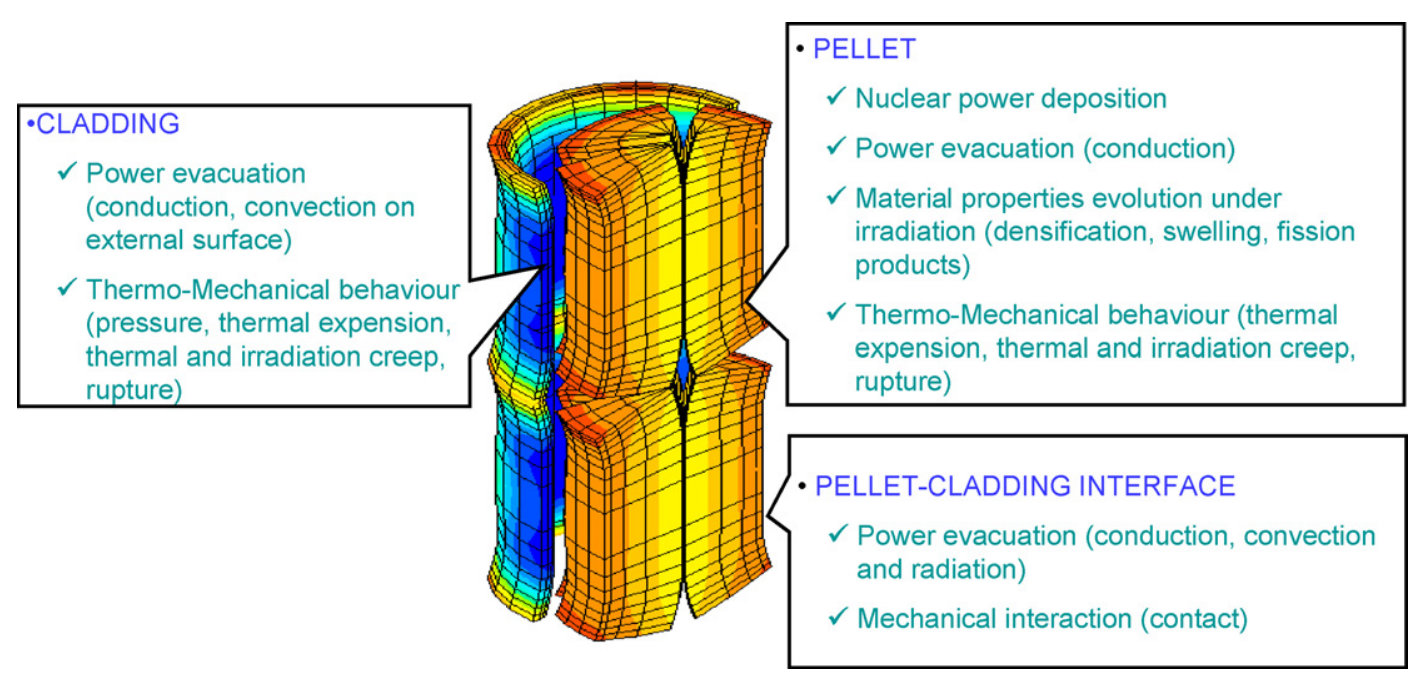

Fig. 1. PWR fuel behaviour modelling. 


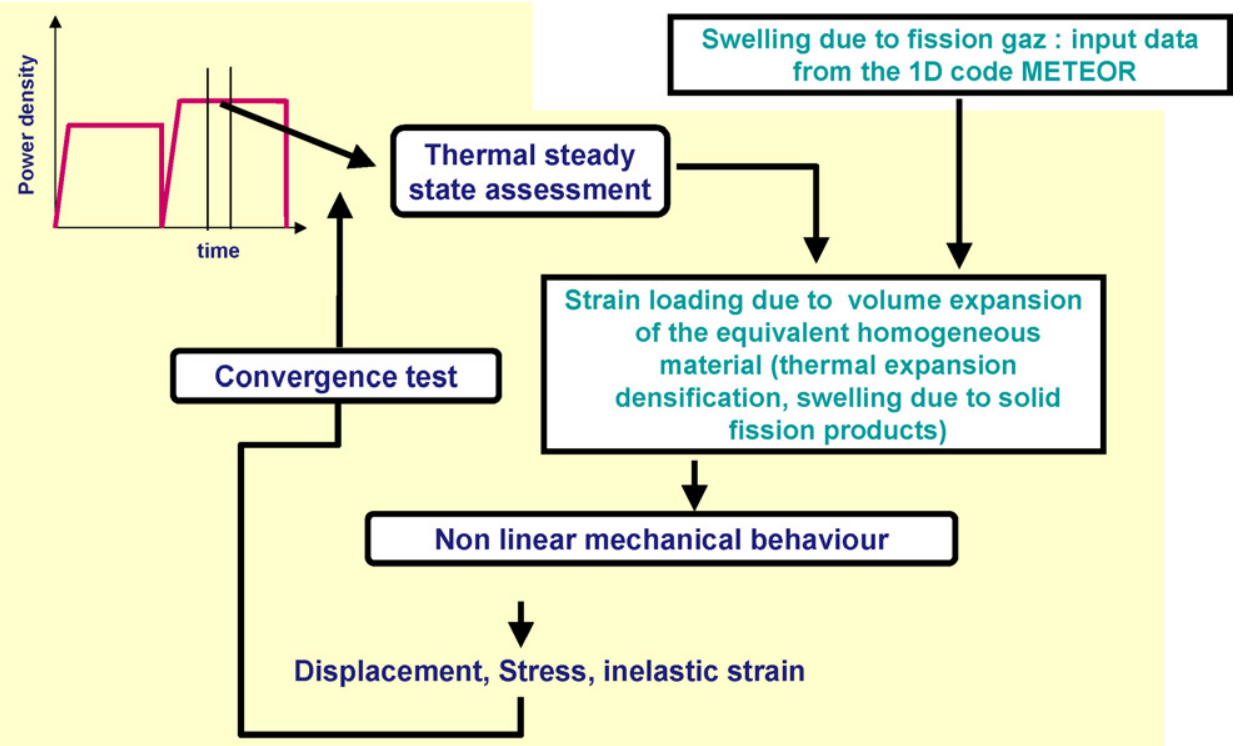

Fig. 2. Numerical integration scheme for the 3D model.

\subsubsection{Cladding}

The non-linear behaviour of the cladding under irradiation is taken into account in the 3D FE model of ALCYONE by a non-unified formulation (Contesti, 1989) coupling a creep law (2) and a plasticity model with linear kinematics hardening (3).

$\frac{\mathrm{d} \varepsilon_{\mathrm{v}}}{\mathrm{d} t}=A\left(J_{2}(\overline{\bar{\sigma}})\right)^{n_{p}} \mathrm{e}^{-\left(Q_{p} / R T\right)} \mathrm{e}^{-B t}+C\left(J_{2}(\overline{\bar{\sigma}})\right)^{n_{s}} \mathrm{e}^{-\left(Q_{s} / R T\right)} \Phi^{p}$

$J_{2}(\overline{\bar{\sigma}}-\overline{\bar{X}})-R_{0} \leq 0$ and $\overline{\bar{X}}=\frac{2}{3} h \overline{\bar{\varepsilon}}_{\mathrm{p}}$

In Eq. (2) $\mathrm{d} \varepsilon_{\mathrm{V}} / \mathrm{d} t$ is the creep strain rate, $\Phi$ the fast neutron flux, $\left(A, n_{p}, Q_{p}, B, C, n_{\mathrm{s}}, Q_{\mathrm{s}}, p\right)$ are material parameters and $R$ is the universal gas constant. In Eq. (3), $\overline{\bar{X}}$ is the internal stress associated to kinematics hardening, $R_{0}$ the yield stress, $h$ the hardening modulus and $\overline{\bar{\varepsilon}}_{\mathrm{p}}$ is the plastic strain.

Creep rate enhancement due to the effect of the fast neutron flux $\Phi(E>1 \mathrm{MeV})$ on the material is taken into account in the second term of Eq. (2) which models stationary creep. The irradiation-induced hardening of the material is introduced in the first term of Eq. (2) which models primary creep and in Eq. (2) by the dependency of the material parameters on neutron fluence. To account for the material behaviour on the whole loading range, two different sets of material parameters are used for creep at low stress level (base irradiation) and creep at high stress level (ramp test). In this study, the anisotropic behaviour of the cladding is not taken into account, although the coefficients of Hill's criterion have already been identified from tests performed under various loading conditions (Soniak et al., 2002). This approximation has been made in order to be consistent with former simulations performed with the 3D model of the TOUTATIS application. The modelling of the cladding behaviour will be improved in the future in order to have a better assessment of the mechanical fields in the cladding.

\subsubsection{Pellet-cladding interface}

Thermal flux through the interface is computed with an equivalent convection exchange coefficient taking into account conduction and radiation when gap is opened, or thermal contact resistance when gap is closed (Lassmann and Hohlefeld, 1987). Concerning mechanical aspects, unilateral contact is assessed by the Lagrangian multiplier method of the CAST3M Finite Element code, and a "Coulomb" type model, with a friction factor of 0.5 , is introduced to take into account friction-slipping or sticking phenomena.

\section{3. $3 D$ representation for $P W R$ fuel component}

In the 3D FE model of ALCYONE, only one fourth of a single pellet fragment and the overlying piece of cladding (see Fig. 3) is meshed. The fuel pellet considered in the simulations is located at the axial position in the rod where the power level is maximum during the power ramp test. The size of the pellet fragment is consistent with post-irradiation examinations performed after two or three cycles of base irradiation (Michel et al., 2007), which show the existence of four to eight pellet fragments in the circumferential direction. The pellet fragment angle $\left(22.5^{\circ}\right)$ has been chosen in order to maximize the magnitude of the fragment "hourglass" shape during nominal loading conditions. It has been shown in Refs. Bentejac (2004) and Michel et al. (2007) that the pellet fragmentation in the axial direction had little impact on the hourglass shape, i.e., the deformations of a continuous fragment under nominal loading are very closed to the deformations of a fragment divided axially in several stacked pieces.

The boundary conditions considered in the 3D calculations are shown in Fig. 3. They account for the geometrical symmetries of the problem and for the pellet-cladding and pellet-pellet interactions. At the inter-pellet plane (plane $0 x_{0} y_{0}$ in Fig. 3), unilateral contact conditions are prescribed $\left(U_{z} \geq 0\right)$. The mechanical reaction of the fissile column above and under 


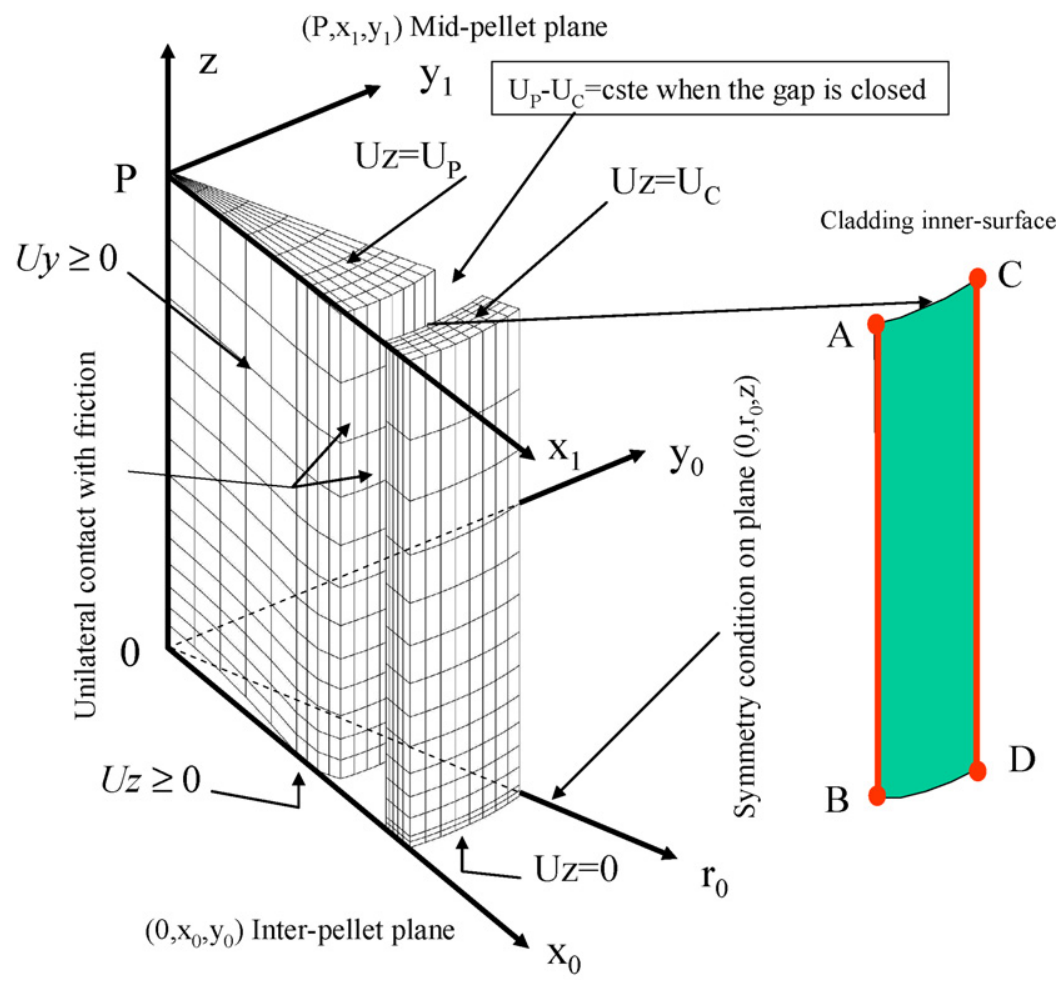

Fig. 3. 3D finite element mesh for PCI: symmetries and boundary conditions.

the meshed fragment is represented by a kinematics relation between the pellet and the cladding mid-planes (plane $\mathrm{P} x_{1} y_{1}$ in Fig. 3). This mid-plane locking condition is applied only when the pellet-cladding gap is closed at least at one point. Concerning loading conditions, the internal pressure (gas pressure) is applied to the cladding inner surface and to the pellet fragment outer surface. The external pressure (water pressure) is applied to the cladding outer surface. Axial pressure due to "end-effects" on the fuel rod is also applied to the cladding mid-plane.

\section{3D analysis of pellet-cladding interaction loading}

\subsection{Experimental irradiation protocol}

Generally the risk of cladding failure due to PCI is analysed according to an experimental protocol (see Fig. 4) where the fuel rod is first submitted to a base irradiation in a power reactor and then to a power ramp test in an experimental reactor. The base irradiation provides the initial state of the fuel elements, before transient loading, with a representative range of burn-up levels. The power ramp test first starts with a pre-conditioning period (AB in Fig. 4), which simulates a nominal loading similar to the one which prevailed at the end of the base irradiation. The transient stage (BC in Fig. 4) takes approximately 1 min (at a power rate of $100 \mathrm{~W} /(\mathrm{cm} \mathrm{min})$ ) and is followed by a holding period (CD in Fig. 4), which lasts between 0 and $12 \mathrm{~h}$, at the maximum power level. The test ends up with a shutdown period.

\subsection{Cladding residual displacement}

Residual displacements of the cladding before and after the power ramp test are measured thanks to non-destructive examinations (Fig. 5). The cladding outer profilometry is an interesting data because it gives quantitative elements on the

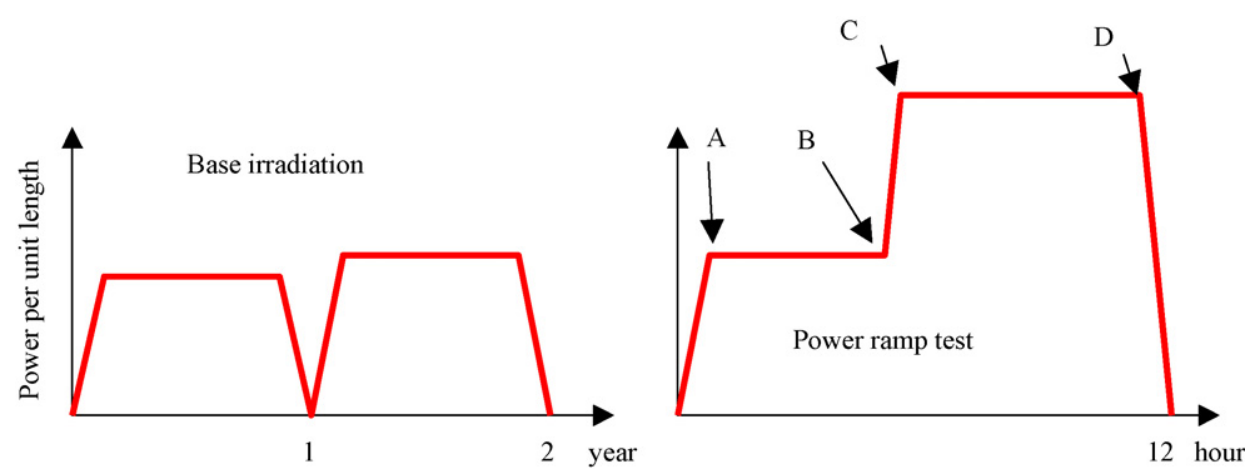

Fig. 4. Experimental protocol for PCI analyses. 


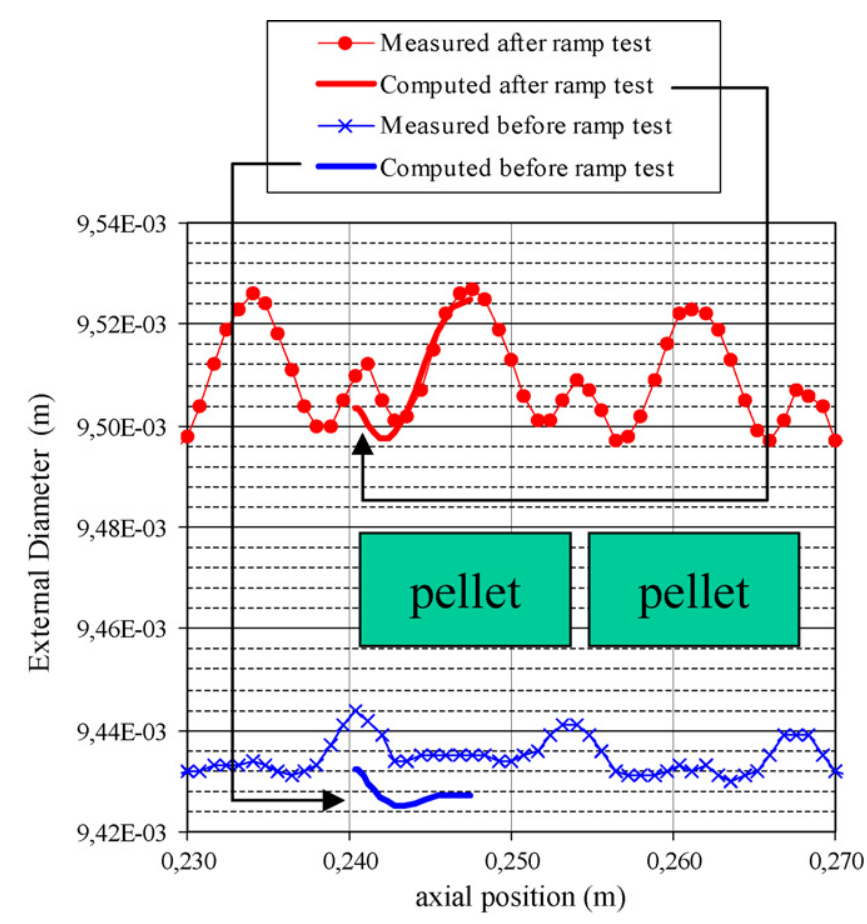

Fig. 5. Experimental and computed axial variations of the cladding outer diameter.

pellet-cladding mechanical interaction which can lead to a significant amount of residual strains in the cladding. Axial variation of the cladding outer diameter is decomposed in three geometrical parameters (see Fig. 5): out of ridge diameter, primary ridge and secondary ridge. The ridging mechanism of the cladding during base and power ramp test irradiations, can be schematically decomposed as following (Michel, 2005):

- During base irradiation the thermal gradient associated to fuel fragmentation lead to close the pellet-cladding gap first at the inter-pellet plane (hourglass shape of the pellet).

- Then the pellet hourglass shape is printed in the cladding because of inelastic strains due to material creep under pressure loading.

- During transient stage viscoplasticity in the centre of the pellet is enhanced due to high temperature, thermal gradient and gaseous swelling. This viscoplasticity tends to fill up the pellet dishing and to reduce radial displacements in the inter-pellet plane area, whereas the viscoplastic flow in the mid-plane area leads mainly to a radial extension. The latter create the secondary ridge observed on the cladding profilometry after a power ramp test.

A comparison between computation and experimental measurements of the cladding outer diameter before and after the power ramp test is also presented in Fig. 5. As shown in the latter, 3D simulation has a good capacity to assess the external cladding profilometry variation after base and ramp test irradiations. This kind of comparison enables us to validate non-linear models (Michel et al., 2007) used in the fuel behaviour simulation code to assess the complex competition process leading to PCI.

\subsection{Cladding rupture due to PCI under transient loading}

A typical rupture of the cladding due to PCI during a power ramp test is illustrated in Fig. 6. Destructive examinations (Mougel et al., 2004) lead to conclude that in each failed rodlet a crack perpendicular to the circumferential direction was detected in the cladding around the inter-pellet plane. Moreover, crack location angle was always linked to the rupture plane between two pellet fragments. These results and simulation lead to invoke several factors in the cladding rupture mechanism. Among these factors we can list:

- Stress corrosion cracking acceleration due to iodine produced in the pellet under irradiation.

- Stress concentration in the cladding due to a pinch effect associated to pellet hourglass shape.

- Strain localisation in the cladding due to crack opening between two pellet fragments.

\subsection{Cladding loading during power ramp test: $3 D$ simulation}

Cladding loading during the power ramp test is analysed through the 3D simulation results of $\mathrm{A} 1$ and $\mathrm{B} 1$ fuel rods submitted to a PCI experimental irradiation protocol described in Table 1. Because of the different pellet type used in fuel rod B1 cladding rupture didn't occur during the power ramp test despite a higher power level at the end of the transient stage. These experimental results will enables us to analyse cladding loading conditions leading or not to a stress corrosion cracking (SCC) type rupture.

Stresses and strains computed at the end of the preconditioning period for fuel rod A1 are presented in Fig. 7. Due to base irradiation and to the preconditioning period the pellet-cladding gap is closed for an important proportion of the interface. In Fig. 7a we can observe that the contact pressure $\left(-\sigma_{r r}\right)$ is higher than the internal pressure $(8 \mathrm{MPa})$ in the area where the gap is closed. Due to contact pressure the mean circumferential stress level is at a value of $10 \mathrm{MPa}$ despite an internal and external pressure difference of $5.5 \mathrm{MPa}$, which should lead to compressive stress level of $55 \mathrm{MPa}$ in a contact free cladding tube. The circumferential stress gradient through the cladding thickness can be mainly explained with a local bending due to an ovalization of the cladding submitted by the pellet to a non-axisymetric displacement loading during the base irradiation. This ovalization tends to increase the circumferential stress applied on the inner-cladding surface in front of the radial crack of the pellet fragment (see Fig. 7), however the magnitude of this local bending is not significant compare to geometrical changes induced by the transient stage (see next section). Cumulated creep strain from the beginning of irradiation has also been plotted in Fig. 7b, these inelastic strains occurred under a low stress level thanks to the activation energy of the fast neutron flux (renvoyer aux equations cstve de la gaine).

Stresses and strains computed at the end of the transient stage are presented in Fig. 8, as expected the temperature gradient through the pellet $\left(1680^{\circ} \mathrm{C}\right.$ at the centre and $410^{\circ} \mathrm{C}$ at the periph- 


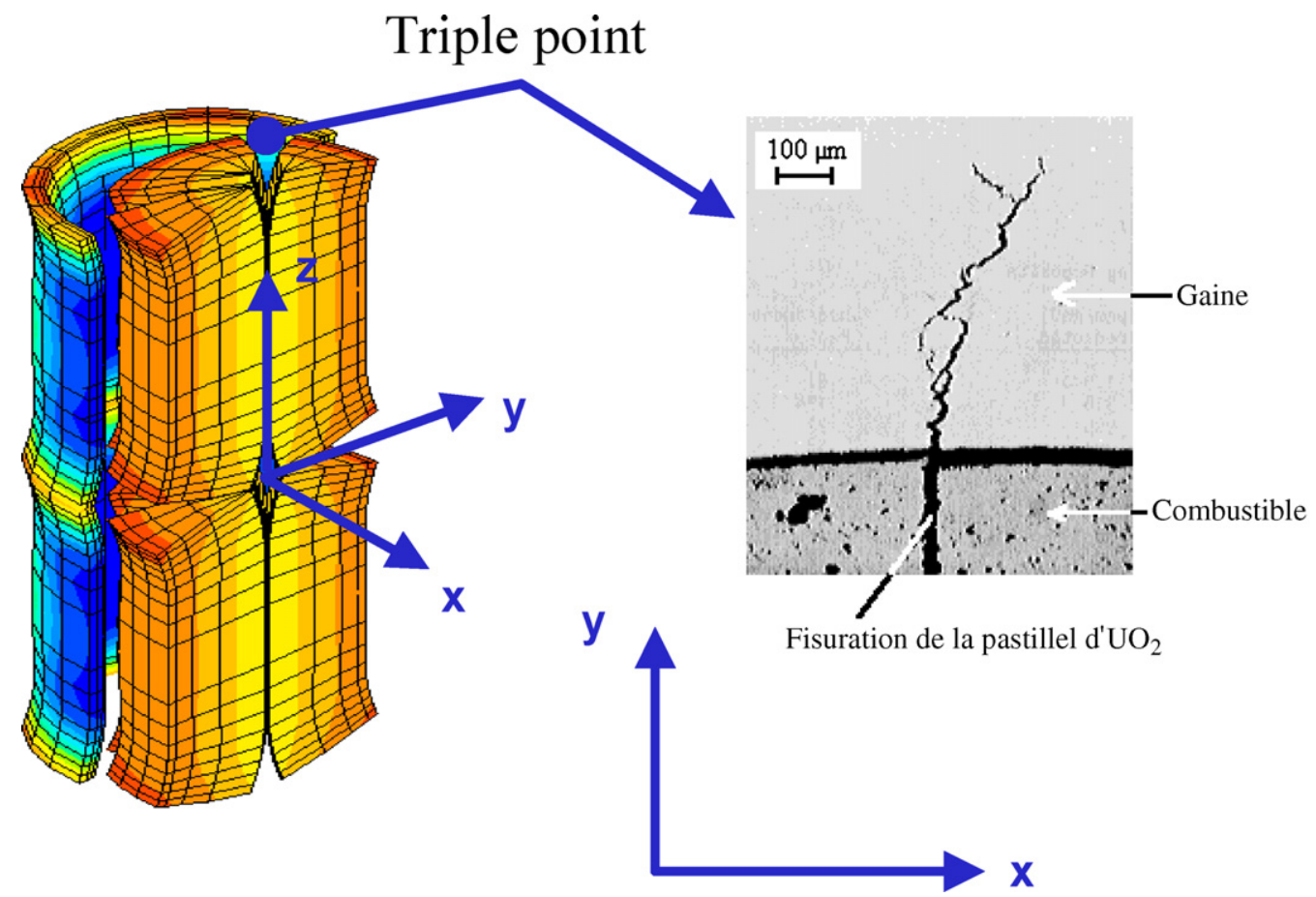

Fig. 6. Cladding rupture due to PCI after a power ramp test.

ery) lead to a volume expansion with an hourglass shape of the pellet fragment. These geometrical changes induce an enhancement of the pressure contact and then a tensile circumferential stress in the cladding (mean value of $\sigma_{\theta \theta}=465 \mathrm{MPa}$ ). In Fig. 8 we can see a pressure contact concentration at the inter-pellet plane $\left(\sigma_{r r}=-160 \mathrm{MPa}\right)$ due to the hourglass shape and the contact discontinuity between two pellets. Concerning stress and strain distribution in the cladding, the high loading level at the triple point (see rupture location in Fig. 6) can be understand through the results of Fig. 8, however it is not obvious to define a criterion which lead to conclude that rupture will occur in this particular area. Moreover, the results computed for the fuel rod B1, presented in Fig. 9, lead to a higher loading level of the cladding at the end of the transient stage, compare to the fuel rod A1, although no rupture occurred for the fuel rod B1 (see Table 1).

This conclusion leads us to analyse the cladding loading level at the end of the transient stage from a different point of view, for this, the normal and the tangential stresses, respectively called $\sigma_{\mathrm{n}}$ and $\sigma_{\mathrm{t}}$, computed in the pellet-cladding interface have been plotted in Fig. 10. These stresses have been derived from the nodal forces, computed in the coulomb friction model according the finite element solver of CAST3M, with Eq. (4). In order to take into account only the tangential loading due to the friction boundary condition, the circumferential component of the nodal forces computed for cladding inner surface nodes submitted to a symmetry boundary condition in the circumferential direction (segments $[\mathrm{AB}]$ and $[\mathrm{CD}]$ in Fig. 3) are considered as equal to zero in Eq. (4). As the tangential stress, according the definition of Eq. (4), can be considered as a pure shearing loading of the interface, it will also be called shearing stress at pellet-cladding interface in the following sections.

$$
\left[\sigma_{\mathrm{n}}\right]=\frac{[\vec{f}][\vec{r}]}{{ }_{\mathrm{S}}[N(x, y, z)] \mathrm{d} s} \text { and }\left[\sigma_{t}\right]=\left|\frac{[\vec{f}][\vec{\theta}]}{{ }_{\mathrm{S}}[N(x, y, z)] \mathrm{d} s}\right|
$$

Table 1

Experimental data for PCI irradiation program

\begin{tabular}{|c|c|c|c|c|c|}
\hline \multirow[t]{2}{*}{ Rodlet } & \multirow{2}{*}{$\frac{\text { Material }}{\text { Pellet/cladding }}$} & \multirow{2}{*}{$\frac{\text { Base irradiation }}{\text { Burn-up (unitary data) }}$} & \multicolumn{3}{|l|}{ Power ramp test } \\
\hline & & & Maximum power level (unitary data) & Time at final power (unitary data) & Cladding rupture \\
\hline A1 & $\mathrm{UO}_{2}$ type $1 / \mathrm{Zy} 4$ & 0.93 & 0.79 & 0.019 & Yes \\
\hline B1 & $\mathrm{UO}_{2}$ type $2 / \mathrm{Zy} 4$ & 1 & 1 & 1 & No \\
\hline $\mathrm{C} 1$ & $\mathrm{UO}_{2}$ type $1 / \mathrm{Zy} 4$ & 0.9 & 0.73 & 1 & No \\
\hline D1 & $\mathrm{UO}_{2}$ type $1 / \mathrm{Zy} 4$ & 0.9 & 0.75 & 0.021 & No \\
\hline E1 & $\mathrm{UO}_{2}$ type $1 / \mathrm{Zy} 4$ & 0.9 & 0.85 & 0.008 & Yes \\
\hline $\mathrm{F} 1$ & $\mathrm{UO}_{2}$ type $1 / \mathrm{Zy} 4$ & 0.9 & 0.81 & 1 & No \\
\hline G1 & $\mathrm{UO}_{2}$ type $1 / \mathrm{Zy} 4$ & 0.8 & 0.88 & 0.167 & Yes \\
\hline H1 & $\mathrm{UO}_{2}$ type $1 / \mathrm{Zy} 4$ & 0.8 & 1 & 0.003 & Yes \\
\hline I1 & $\mathrm{UO}_{2}$ type $2 / \mathrm{Zy} 4$ & 1 & 0.87 & 1 & No \\
\hline
\end{tabular}



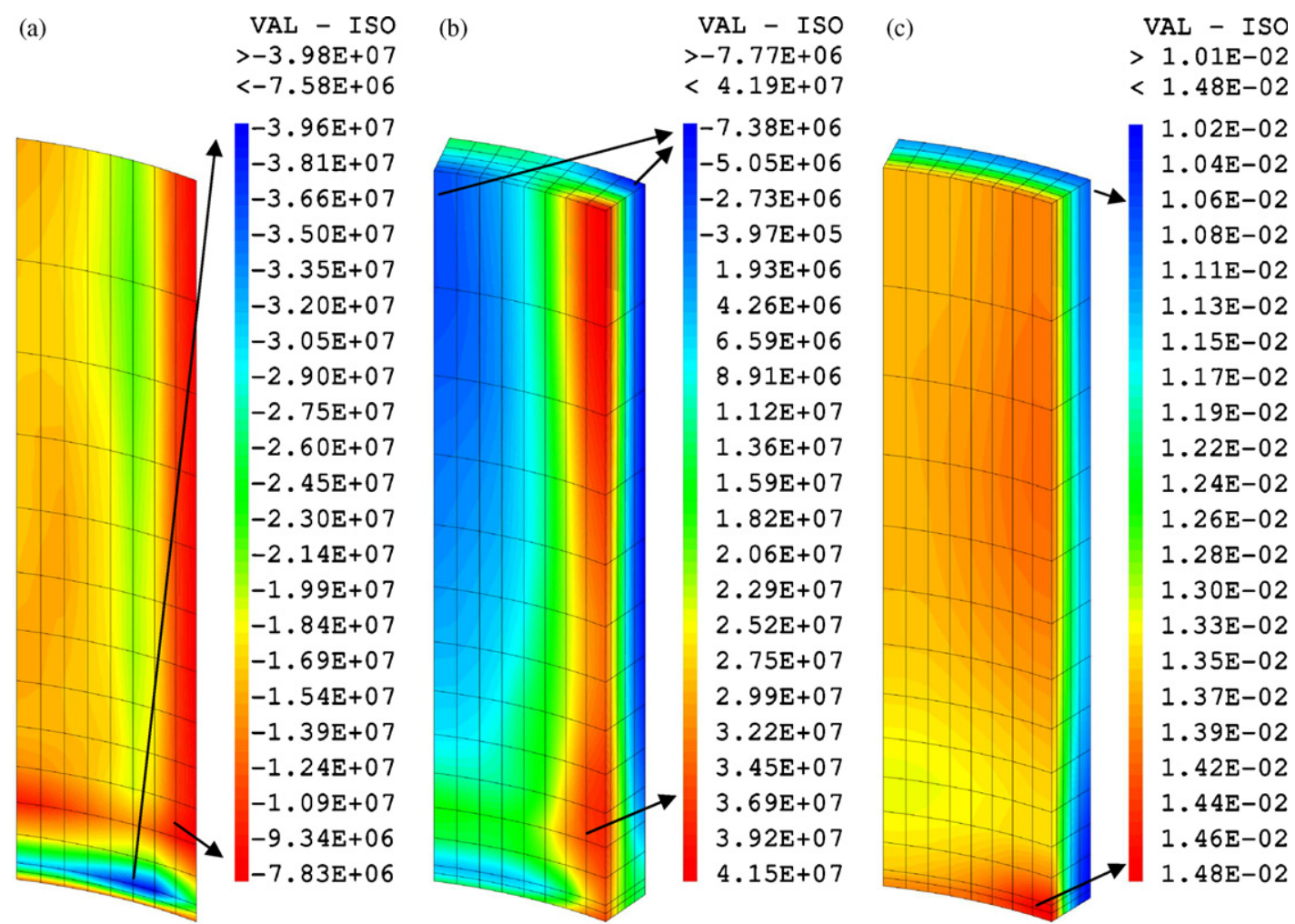

Fig. 7. Mechanical stress and strain fields in the cladding of rodlet $\mathrm{A} 1$ at the end of the pre-conditioning period: (a) $\sigma_{r r}$ stress (Pa) at pellet-cladding interface, (b) circumferential stress $\sigma_{\theta \theta}(\mathrm{Pa})$ in the cladding and (c) equivalent cumulated creep strain in the cladding from the beginning of irradiation.
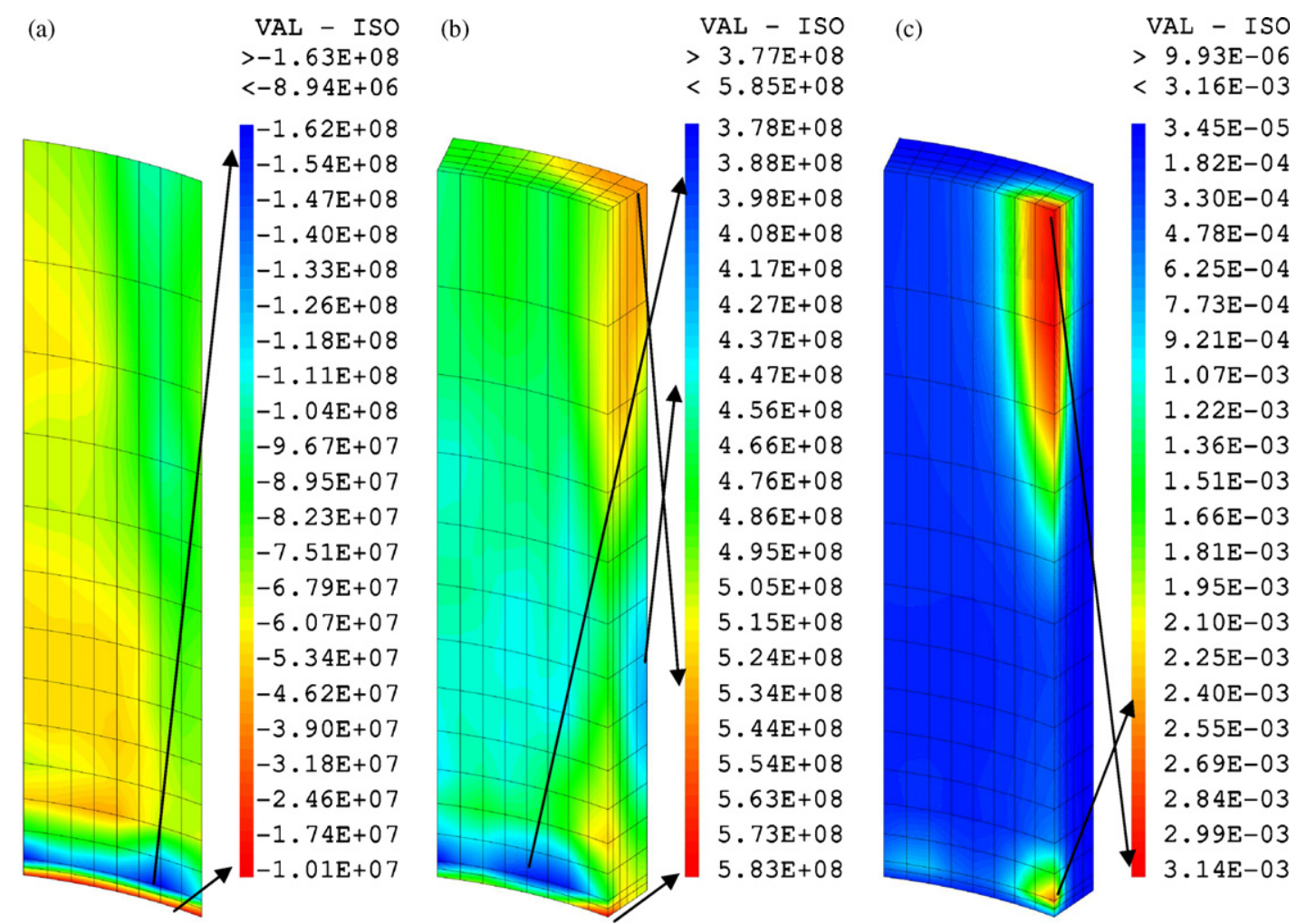

Fig. 8. Mechanical stress and strain fields in the cladding of rodlet A1 at the end of the transient stage: (a) $\sigma_{r r}$ stress (Pa) at pellet-cladding interface, (b) circumferential stress $\sigma_{\theta \theta}(\mathrm{Pa})$ in the cladding and (c) equivalent cumulated creep strain variation in the cladding during the power transient. 

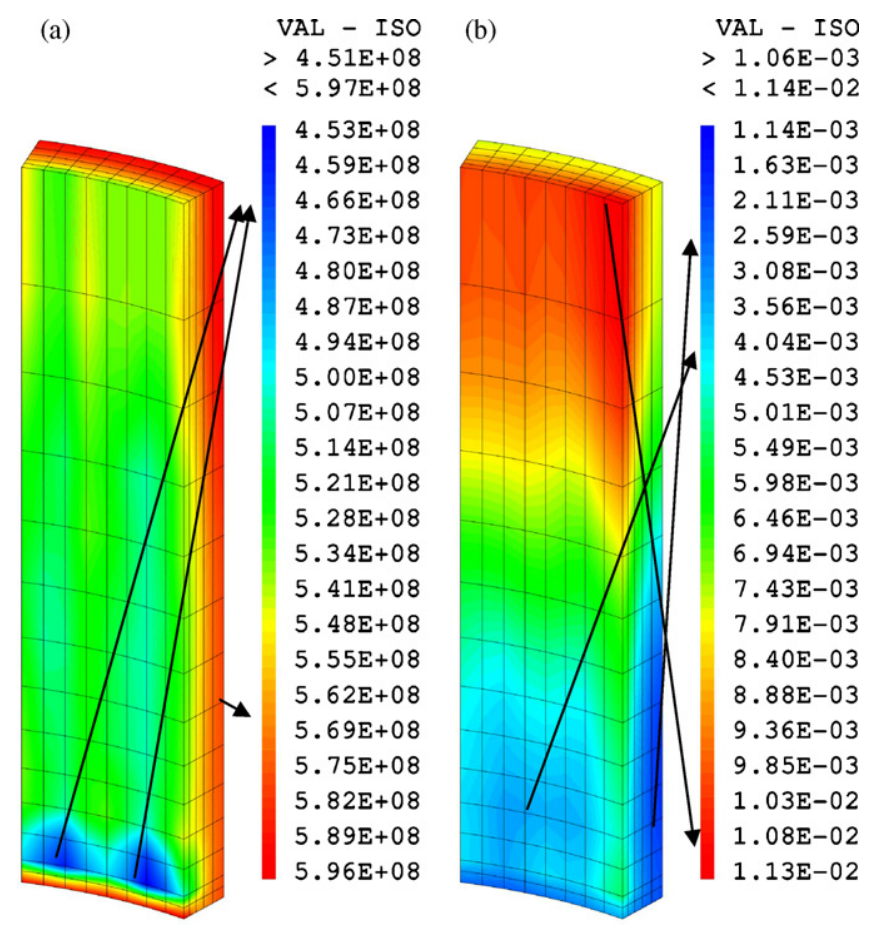

Fig. 9. Mechanical stress and strain fields in the cladding of rodlet B1 at the end of the transient stage: (a) circumferential stress $\sigma_{\theta \theta}(\mathrm{Pa})$ in the cladding and (b) equivalent cumulated creep strain variation in the cladding during the power transient.
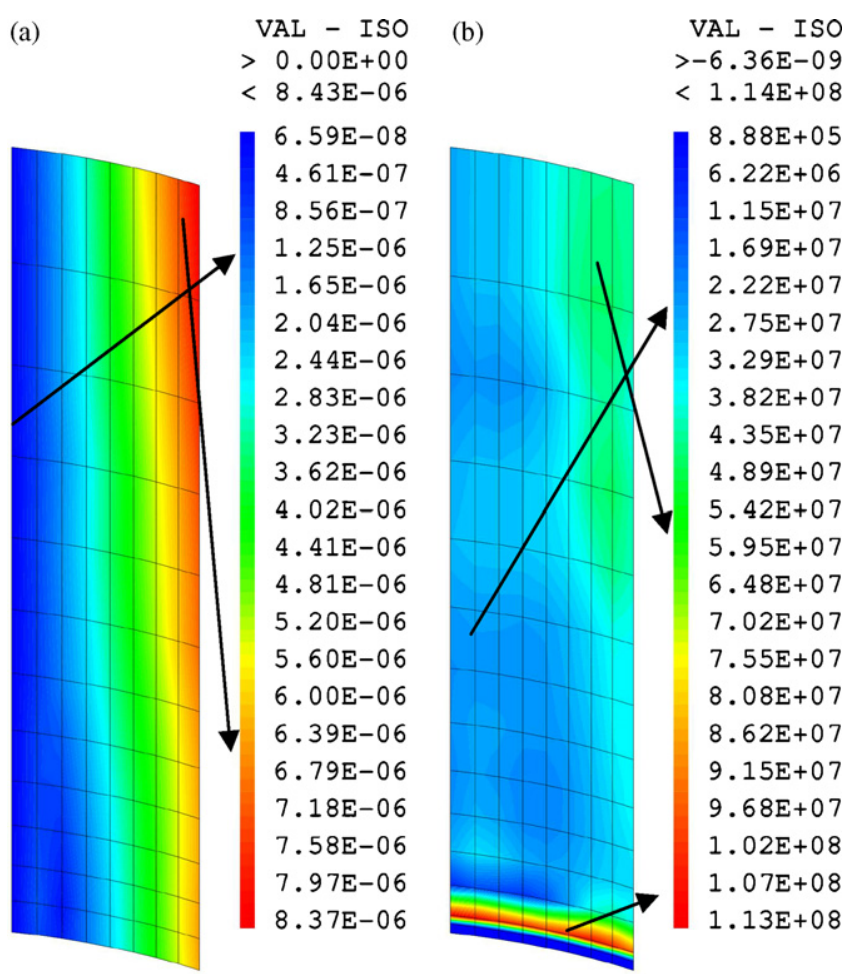

Fig. 11. Loading parameters at the end of the transient stage in the pellet-cladding interface of fuel rod A1: (a) circumferential component of the displacement discontinuity between pellet and cladding (m) and (b) sliding yield stress according the coulomb friction model $(\mathrm{Pa})$.

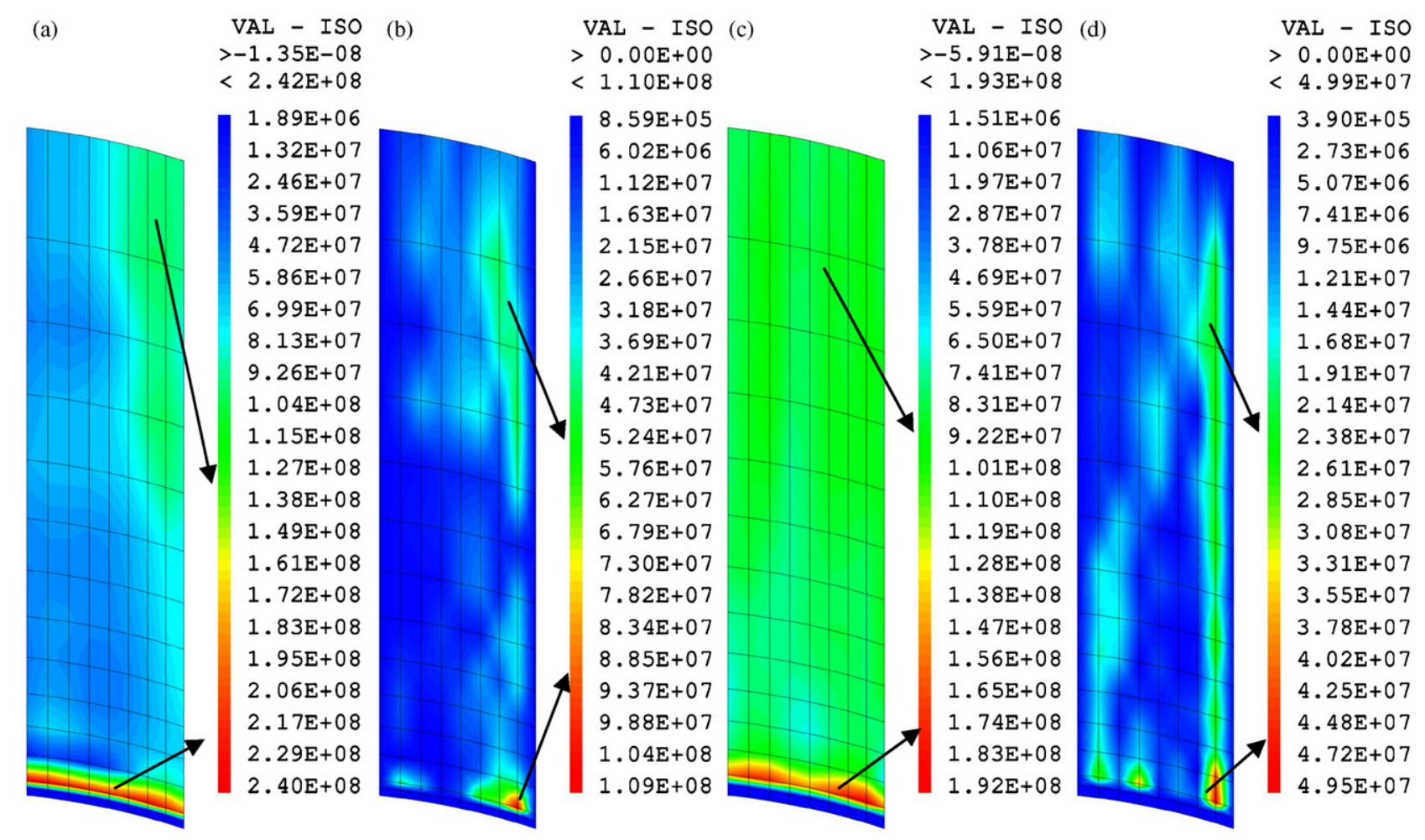

Fig. 10. Normal and tangential loading at pellet-cladding interface at the end of the transient stage: (a) fuel rod A1: normal stress $\sigma_{\mathrm{n}}(\mathrm{Pa})$ at the inner-surface of the cladding, (b) fuel rod A1: circumferential component of the tangential stress $\sigma_{\mathrm{t}}(\mathrm{Pa})$ at the inner-surface of the cladding, (c) fuel rod B1: normal stress $\sigma_{\mathrm{n}}(\mathrm{Pa})$ at the inner-surface of the cladding and (d) fuel rod B1: circumferential component of the tangential stress $\sigma_{\mathrm{t}}(\mathrm{Pa})$ at the inner-surface of the cladding. 
with $\left[\sigma_{\mathrm{n}}\right]$ a symbolic definition of a nodal vector, $\vec{f}$ the nodal force at pellet-cladding interface, $\vec{r}, \vec{\theta}$ unit radial and circumferential vectors, $N(x, y, z)$ the finite element interpolation functions and $S$ the inner cladding surface.

If we consider now the cladding loading according the results of Fig. 10 we can see that the tangential stress distribution for the fuel rod A1 is consistent with crack location of Fig. 6. Moreover the maximum tangential stress at pellet-cladding interface is equal to $110 \mathrm{MPa}$ in fuel rod $\mathrm{A} 1$, which is approximately twice the value reached in fuel rod B1 (50 MPa). The a critical value of the shearing stress at pellet-cladding interface can be defined according the rupture/non-rupture respectively observed for fuel rods A1 and B1 (Table 1). Another interesting point of these results concerns the interpretation of the maximum tangential stress location, as we can see in Fig. 11 the triple point is at the intersection between two lines defining respectively in the interface: the maximal displacement discontinuity, and the maximal sliding yield stress.

The conclusion of this first analyse is that an interpretation of PCI behaviour of fuel rods A1 and B1 is possible if we consider that the shear stress at pellet-cladding interface is a first order parameter in the PCI rupture criterion. For this the link between the global loading in the interface and the local stress-strain field is analysed in the next section.

\section{Local loading at pellet-cladding interface}

\subsection{Stress concentration in the cladding}

The load transfer between the pellet and the cladding can be first outlined by the consideration of the main numerical results of Ref. Roberts (1978), summarized in Fig. 12. In Ref. Roberts (1978), an analytical solution is proposed for the 2D plane strain analysis of an elastic cladding element submitted to a combined internal pressure and shear loading. The numerical results presented in the paper (Roberts, 1978) give the evolution of the circumferential stress $\sigma_{\theta \theta}$ in the thickness of the cladding

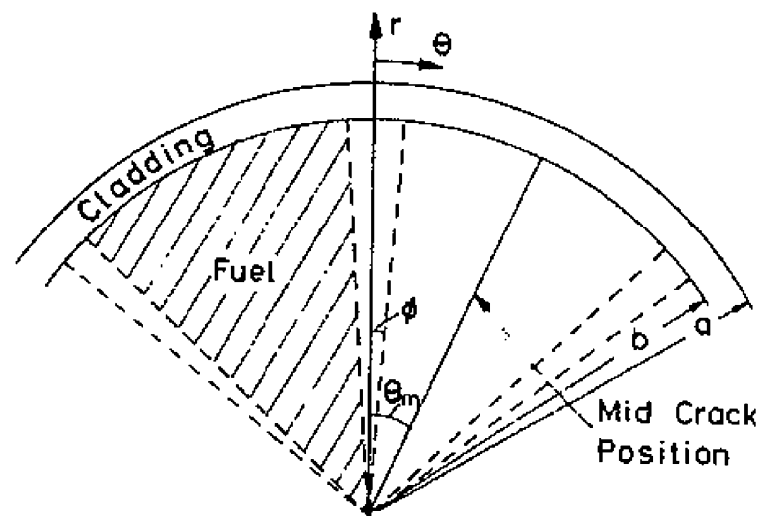

Fig. 12. Two-dimensional $(r, \theta)$ generalized plane strain configuration for PCI finite element analysis.

and in front of the tip of the pellet fracture (see Fig. 12), as obtained from calculations performed with and without friction at the pellet-cladding interface. As illustrated in Fig. 13, these results show that a shear stress level of $16 \mathrm{MPa}$ (see Fig. 5 of Ref. Roberts, 1978) leads to enhance from 90 to $180 \mathrm{MPa}$ the hoop stress (see Fig. 4 of Ref. Roberts, 1978). The simplified solution given in Ref. Roberts (1978) cannot be extended easily to non-linear material behaviour. Hence, in order to show the impact of the cladding viscoplasticity and of PCI loading on the local stress concentration in the cladding, 2D generalized plane strain computations have been performed with the $2 \mathrm{D}_{r, \theta}$ application of ALCYONE which models the behaviour of the mid-pellet plane of a fuel pellet. The coarse and fine meshes (minimum size of element around $1 \mu \mathrm{m}$ ) used in the simulations together with the applied boundary conditions are described in figure. The coarse mesh has radial and tangential discretizations similar to that of the 3D mesh. The fine mesh presents on the contrary non-constant radial and tangential element sizes which are strongly reduced in the vicinity of the pellet fracture plane. This refinement is applied in order to assess the local stress concentration in the cladding in contact with the tip of the pellet fracture. The minimum size of the pellet or cladding elements

\section{G. Roberts / Stress concentration in cladding}
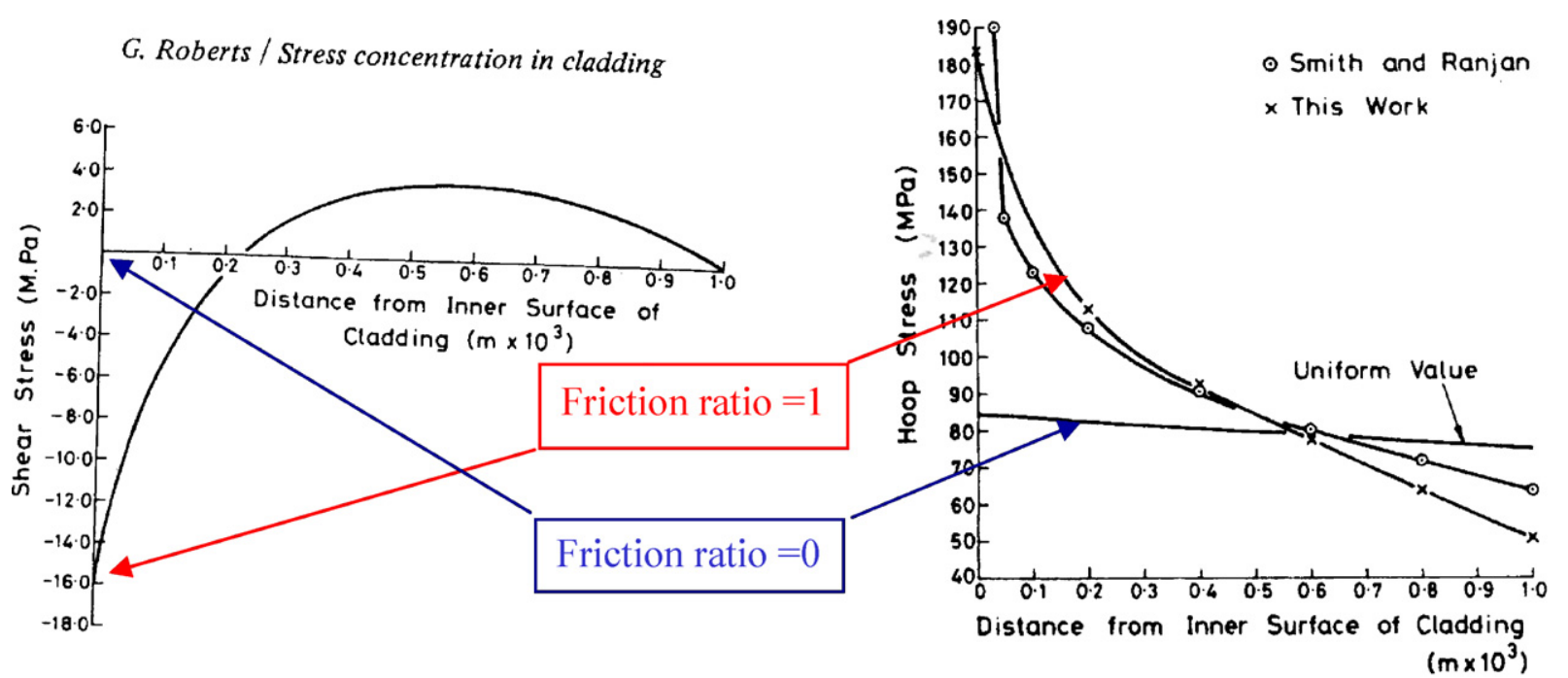

Fig. 13. Circumferential stress through the cladding thickness: impact of the friction ratio (credit Roberts, 1978). 


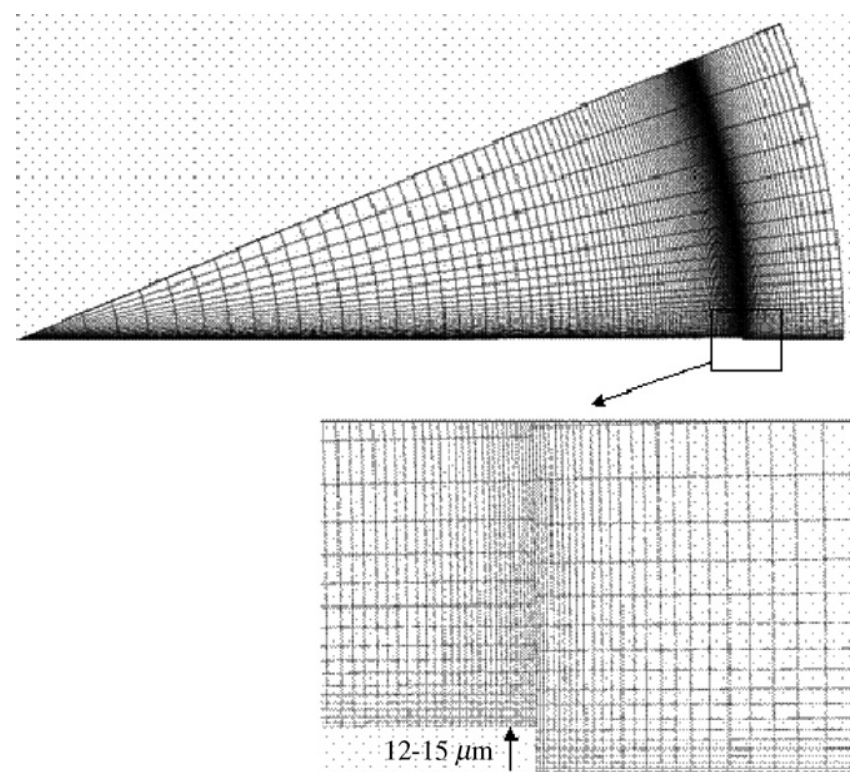

Fig. 14. Deformations of the A1 pellet and cladding element at the end of the transient phase of the power ramp test.

is around $1 \mu \mathrm{m}$. The $2 \mathrm{D}_{r, \theta}$ simulations have been undertaken for fuel rod A1 and B1 with the material models and properties used in the 3D simulations (fuel cracking, cladding viscoplastic behaviour, etc.).

The deformation of the pellet and the cladding elements in the vicinity of the pellet fracture tip, as obtained at the end of the transient stage of the power ramp test (point $\mathrm{C}$ in Fig. 4) from the simulation of fuel rod A1 with the fine mesh are presented in Fig. 15. Similar results have been obtained for fuel rod B1. The tangential displacement at the pellet crack tip resulting from the opening of the fracture can be estimated from Fig. 14 at $12-15 \mu \mathrm{m}$. The opening of the fracture leads in turn to the punching of the cladding element by the pellet crack tip. A description of the resulting local stress concentration in the cladding requires therefore a sufficiently refined finite element mesh (element size at least five times smaller than the opening of the pellet crack), as shown by Fig. 16 in which the evolution of hoop stress in the

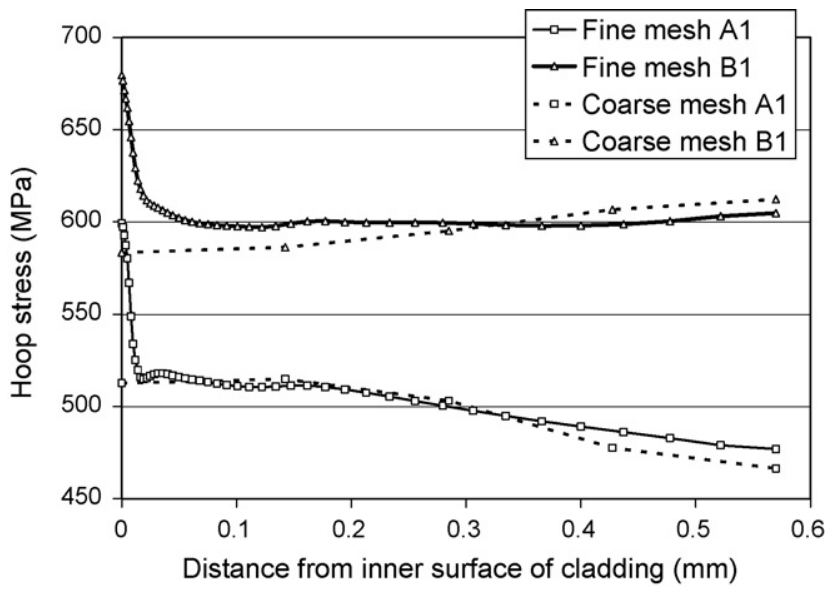

Fig. 16. Coarse mesh, fine mesh and boundary conditions used in the $2 \mathrm{D}_{r, \theta}$ simulations.

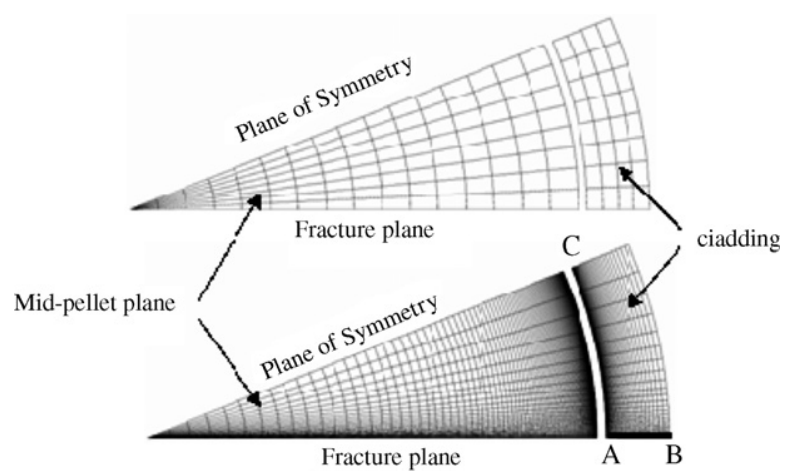

Fig. 15. Evolution of the hoop stress in the thickness of the cladding (line AB in Fig. 12b) at the end of the transient phase of the power ramp test.

thickness of the cladding element (line AB in Fig. 15) is plotted for the simulations of fuel rods A1 and B1 performed with the coarse and fine meshes. While the coarse mesh simulations provide good estimates of the mean hoop stresses in the cladding, only the fine mesh calculations are able to describe the local stress concentration occurring at the cladding inner surface. The former lead to underestimate the maximum hoop stresses by about $100 \mathrm{MPa}$.

The evolution of the normal and tangential stresses at the pellet-cladding interface (line AC in Fig. 15), as obtained from the $2 \mathrm{D}_{r, \theta}$ simulation of fuel rods $\mathrm{A} 1$ and $\mathrm{B} 1$ performed with the fine mesh, are presented in Fig. 17. Recalling that the $2 \mathrm{D}_{r, \theta}$ plane strain model describes the behaviour of the mid-pellet plane and not of the inter-pellet plane where SCC failures occur, it explains why the local maximum normal and shear stresses (respectively, $100-150$ and $20-40 \mathrm{Mpa}$ ) from the $2 \mathrm{D}_{r, \theta}$ simulations are much smaller than that obtained in the 3D simulations (respectively 190-240 and 50-110 MPa, see Fig. 10). The stress concentration shown in Fig. 16 can therefore not be used directly to compare the SCC behaviour of fuel rods A1 and B1. Hence, 2D simulations based on the inter-pellet 3D shear stresses have been performed and are presented in the next section.

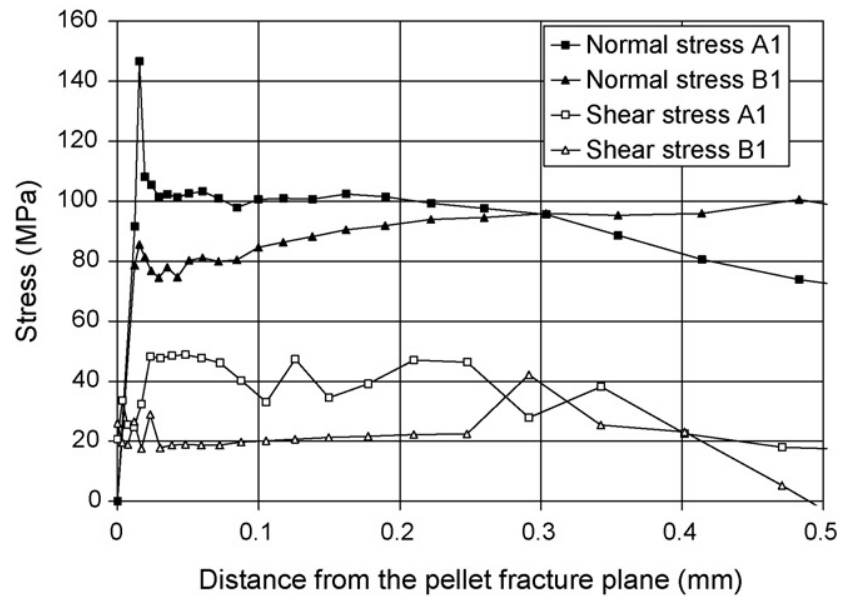

Fig. 17. Evolution of the normal and shear stresses at the pellet-cladding interface at the end of the transient phase of the power ramp test. 


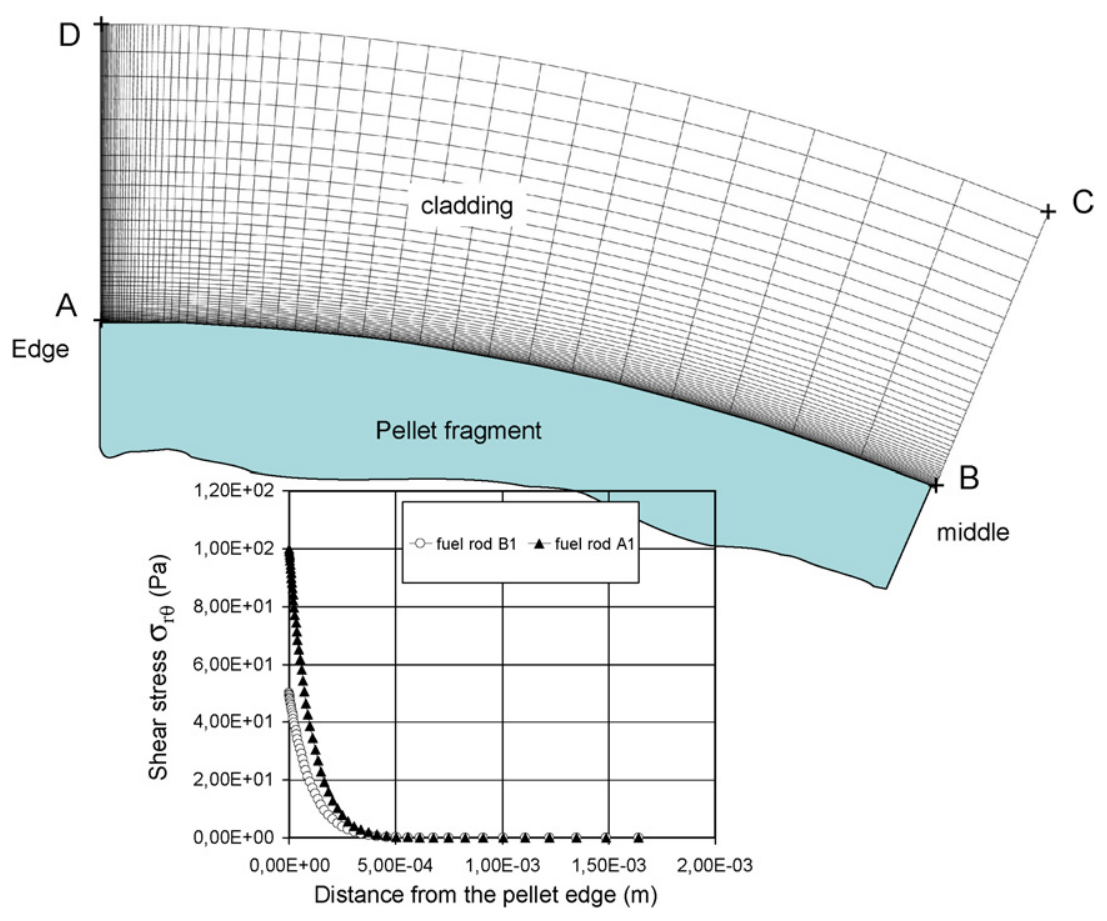

Fig. 18. Two-dimensional plane strain model of the cladding.

\subsection{Impact of the shear stress at pellet-cladding interface}

To quantify the impact of the interfacial shear stress on local stress in the cladding a 2D plane strain model of the cladding has been used (see Fig. 18). To take into account PCI loading during the transient stage of the power ramp test the following boundary condition are used:

- an internal contact pressure (segment AB Fig. 18) equal to the mean value computed in the $3 \mathrm{D}$ model $(70 \mathrm{MPa}$ for fuel A1 and $84 \mathrm{MPa}$ for fuel rod B1),

- an external pressure (segment DC Fig. 18) of the coolant fluid (13.5 MPa),

- a shear stress $\sigma_{r \theta}$ at pellet-cladding interface (segment AB Fig. 18) as a decreasing function of the distance from the pellet edge (see Fig. 18). The maximal value is derived from 3D computation results presented in Fig. 10 (100 MPa for fuel rod A1 and $50 \mathrm{MPa}$ for fuel rod B1),

- symmetry boundary conditions on both edges.

In this study the gap between two pellet fragments is not taken into account, and the global loading due to the pellet is approximated with a constant contact pressure on the whole inner cladding surface and a boundary shear stress level computed with the following Eq. (5):

$\sigma_{r \theta}(x)=\sigma_{r \theta}^{\max }(1-x)^{15}$

with $\sigma_{r \theta}^{\max }$ the maximal value of the shear stress computed at pellet-cladding interface in the 3D model and $x$ the curvilinear distance from the pellet edge normalized to unity for an angular portion of $22.5^{\circ}$. These simplifications have been pro- posed because the aim of such a model is to represent a stress concentration at a macroscopic scale (structural effect), and not to assess microscopic stress fields at the scale of the material microstructure.

The loading history is only represented during the transient stage, and is simplified by a proportional loading up to the maximal value computed with the 3D model at the end of the transient stage (see loading boundary conditions above). Moreover, it is considered that the initial cladding stress state is approximately equal to zero, according 3D computation results at the end of the pre-conditioning period. The cladding behaviour is the same than the 3D model (Section 2.2.2), and thermal loading is also extracted from 3D computations.

The circumferential stress $\left(\sigma_{\theta \theta}\right)$ distribution through the cladding thickness (segment AD in Fig. 18), computed at the end of the transient stage for both global loading of fuel rods A1 and B1, is plotted in Fig. 19. As shown in the latter the maximal stress in the cladding is equal to $1.24 \sigma_{\mathrm{o}}$ and $1.14 \sigma_{\mathrm{o}}$ for fuel rods A1 and B1 respectively, which is consistent with the experimental cladding rupture observed in fuel rod A1 (Table 1). As expected with the analysis of the interfacial shear stress (Section 3.4), despite a lower mean circumferential stress level in fuel rod A1 compare to fuel rod B1, the stress concentration lead to a local stress state consistent with experimental results. These results lead us to conclude that the stress concentration in the cladding is proportional to the shear stress transmitted at pellet-cladding interface. Then the peak stress reached in the cladding depends on the contact pressure and also the interfacial shear stress.

These $2 \mathrm{D}$ results have also been used to understand why the $3 \mathrm{D}$ computation cannot assess a local stress level greater in fuel rod A1 than fuel rod B1. The stress concentration zone, shown in Fig. 19, in the cladding is approximately 20-30 $\mu \mathrm{m}$, 


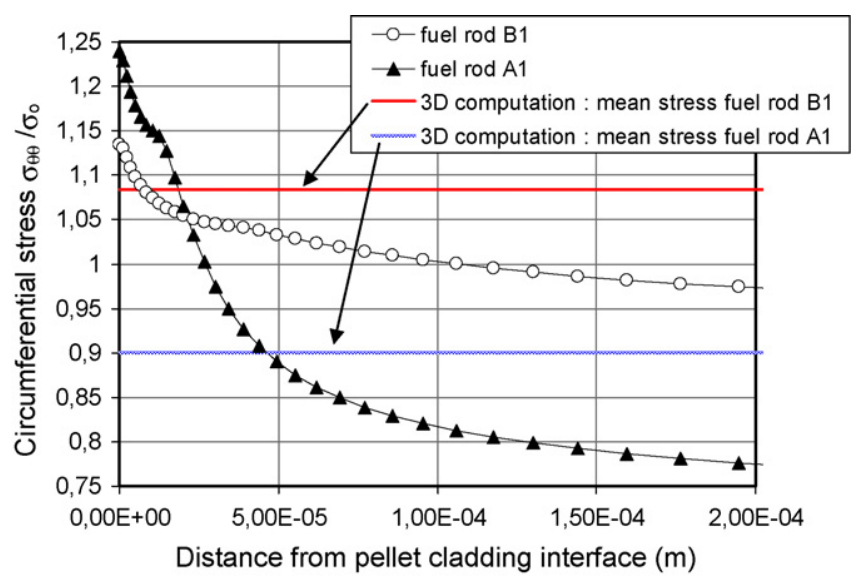

Fig. 19. Circumferential stress through the cladding thickness (segment AD in Fig. 18) at the end of the transient stage (normalized with the cladding yield stress $\sigma_{\mathrm{o}}$ ).

this length is smaller than the finite element size used in the 3D mesh $(\approx 50 \mu \mathrm{m})$. In Fig. 20 maximal values around the triple point computed in the 3D model have been compared to maximal values and local mean values of a $50 \mu \mathrm{m}$ thickness zone in the 2D model. As shown in Fig. 20 the local mean values of the 2D model are consistent with the maximal values of the 3D model. This means that the 3D mesh refinement is not sufficient enough to assess stress concentration in the cladding of fuel rod $\mathrm{A} 1$, and also that the local stress value computed in the $3 \mathrm{D}$ model could not be used easily to discriminate PCI behaviour of fuel rods $\mathrm{A} 1$ and $\mathrm{B} 1$.

\subsection{PCI failure criterion}

Simulations of Section 4.2 lead to conclude that for the 3D computation the local stress level in the cladding can be indirectly derived from the global loading transmitted at pellet-cladding interface. This global loading can be characterized by two parameters: the contact pressure and the interfacial shear stress. The former is linked to the mean circumferential stress in the cladding (as a tube under pressure), and the latter will have a first order effect on circumferential stress concentration in the vicinity of pellet-cladding interface. Then, the main

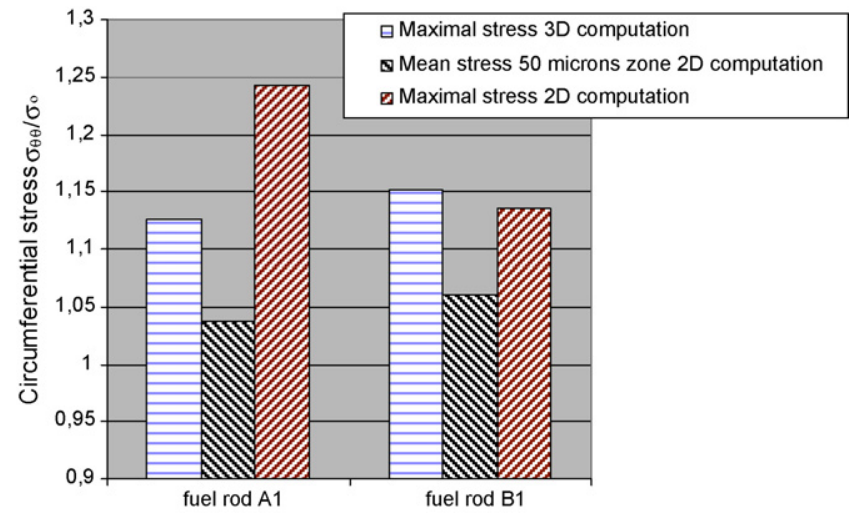

Fig. 20. Local stress assessment in the cladding at the end of the transient stage: comparison of 3D and 2D results (normalized with the cladding yield stress $\sigma_{\mathrm{o}}$ ). idea of the proposed phenomenological criterion is to use a failure curve based on two global loading parameters which are: the mean circumferential stress in the cladding, and the interfacial shear stress loading at pellet-cladding interface. This failure curve can be considered as a global criterion given an equivalent assessment of the peak stress value reach in the cladding.

In order to have a first estimation of the shape of this failure curve, the 2D computation model of Fig. 18 has been used. For this, the global loading transmitted by the pellet to the cladding has been decomposed with the mean circumferential stress through the thickness and the interfacial shear stress as proposed above. Then, for each loading condition the maximal value of the circumferential stress at cladding inner surface has been computed. With these results an iso-stress curve has been build in Fig. 21. In the latter the representative points of fuel rods $\mathrm{A} 1$ and $\mathrm{B} 1$ have also been plotted with a global loading given by 3D computations. As shown in Fig. 21, the circumferential stresses at cladding inner surface of fuel rods A1 and B1 are respectively $1.24 \sigma_{\mathrm{o}}$ and $1.14 \sigma_{\mathrm{o}}$ according the stress distribution plotted in Fig. 19. The shape of this iso-stress curve for a mean circumferential stress lower than $1.08 \sigma_{\mathrm{o}}$ is consistent with the strong impact of the interfacial shear stress level on the risk of failure (as observed for experimental results of fuel rods A1 and B1). For instance, if we consider that the maximal allowable stress is given by fuel rod A1, the mean circumferential stress can increase from $0.79 \sigma_{\mathrm{o}}$ to $1.08 \sigma_{\mathrm{o}}$ when the interfacial shear stress is divided by two (from $0.2 \sigma_{\mathrm{o}}$ to $0.1 \sigma_{\mathrm{o}}$ ). For a mean circumferential stress greater than $1.08 \sigma_{0}$, the impact of the interfacial shear stress is reduced due to the fact that widespread viscoplasticity in the cladding thickness tends to avoid stress concentration in the vicinity of the cladding inner-surface (see Fig. 22).

The use of a local stress criterion to define this PCI failure curve can be discussed through the study of Ref. Rousselier et al. (1999). In the latter the crack arrest conditions, that enable to explain the yield effect observed on stress corrosion cracking failures due to PCI, are strongly linked to the peak stress value at the end of the transient stage and to the relaxation process when the intergranular crack propagation crosses the stress concentration zone. The global PCI failure curve proposed in this study can be considered as a simplified description of the crack arrest phenomenon-proposed in Ref. Rousselier et al. (1999), because the relaxation of stress concentration is not described with the local peak stress criterion. The impact of this simplification will probably lead to an approximate shape of the PCI failure curve, which is under estimated for the low values of the mean circumferential stress, and over estimated for the high values of the mean circumferential stress. In this first step model this simplification seems acceptable, as far as the PCI failure curve will be identified directly on experimental results obtained for the whole database of power ramp tests. The relaxation of stress concentration will probably have to be considered in the next step criterion, in order to have a less empirical approach and to be able to identify the PCI failure curve with laboratory test specimens. At least, the objective of this first step criterion is to have a phenomenological approach in order to be able to assess PCI failure, according the domain of validity given by the 


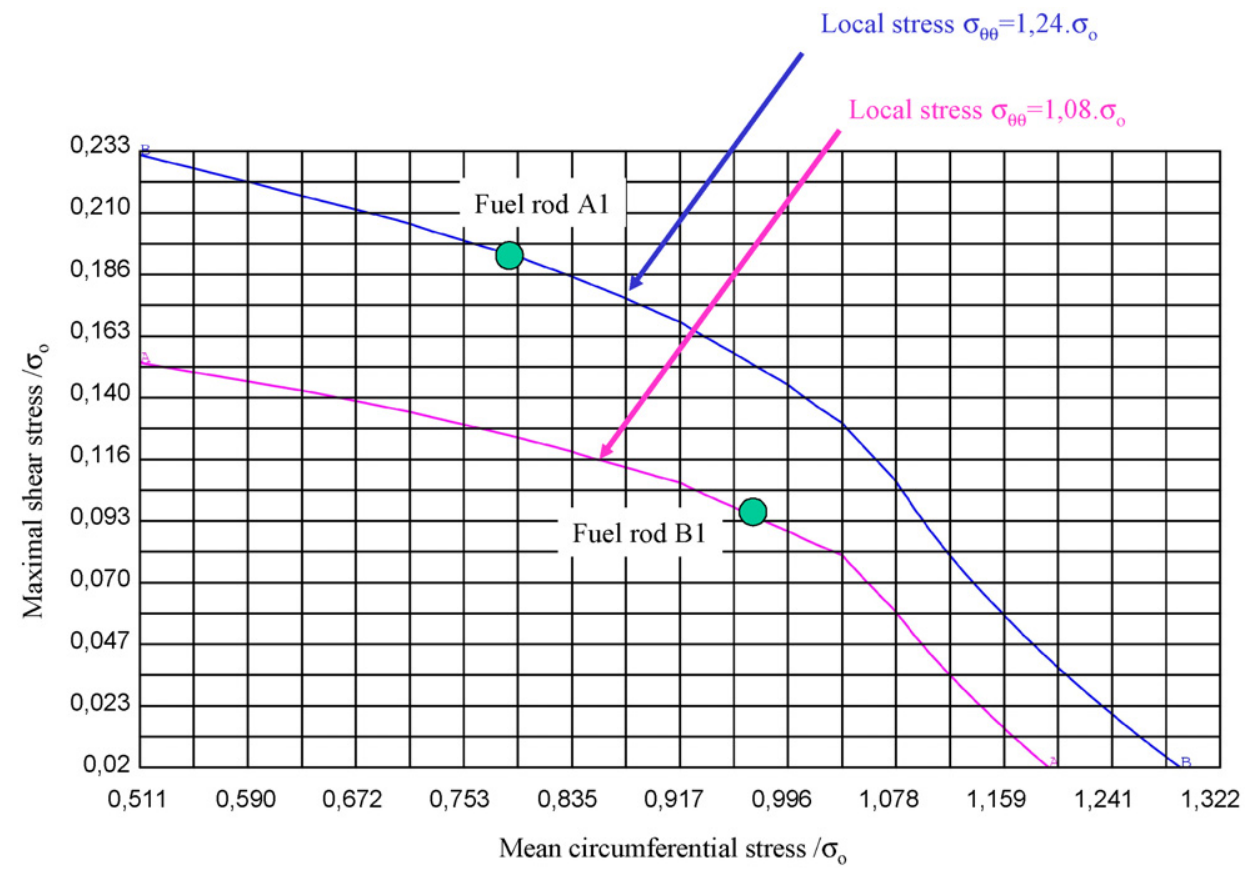

Fig. 21. Iso-loading curves at the end of the transient stage: maximal value of the local stress in the cladding inner surface versus the cladding mean circumferential stress and the interfacial shear stress (normalized with the cladding yield stress $\sigma_{\mathrm{o}}$ ).

power ramp test experimental database, and also to understand the loading conditions prescribed by the pellet.

\section{Interpretation of the power ramp test experimental database}

\subsection{Loading parameters and experimental PCI failure curve}

An empirical assessment of the PCI failure curve, discussed in the previous section, has been derived from the power ramp

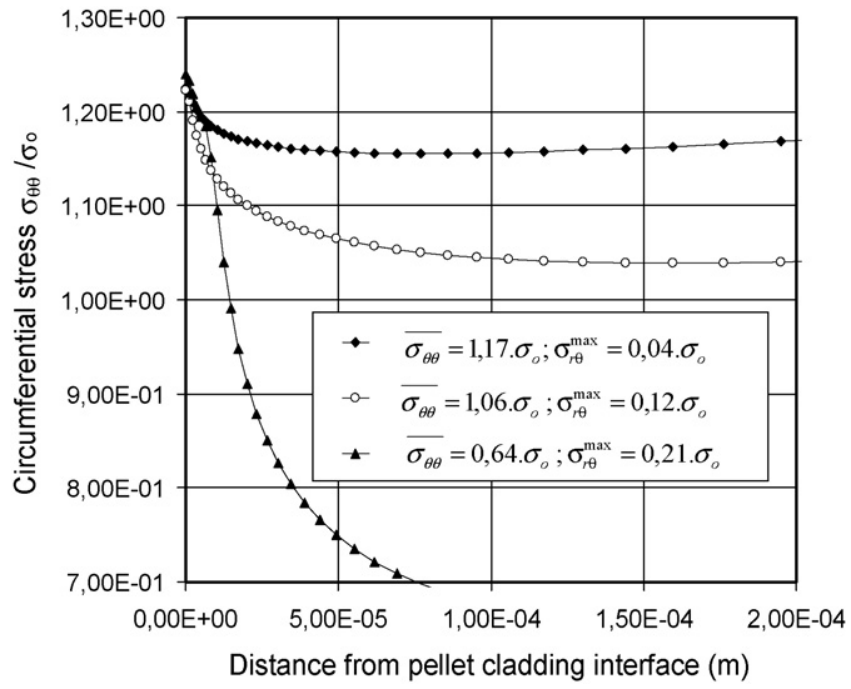

Fig. 22. Stress distribution through the cladding thickness at the end of transient stage versus the global loading composed of the mean circumferential stress $\overline{\sigma_{\theta \theta}}$ and the maximal interfacial shear stress $\sigma_{r \theta}^{\max }$ normalized with the cladding yield stress $\sigma_{0}$. test experimental database of Table 1. For this, 3D simulations of the base + power ramp test irradiations have been achieved for each fuel rod with the ALCYONE PWR fuel code. Then, the global loading parameters proposed in Section 4.3 have been computed at the end of the transient stage. Concerning the interfacial shear loading, the maximal shear stress at cladding inner surface has been replaced by the energy density due to circumferential friction forces during the transient stage. This parameter, called $W_{r \theta}$, is computed with the energy dissipated at pellet-cladding interface, divided by the surface of a potential through wall crack in the cladding as detailed in the following Eq. (6).

$W_{r \theta}=\frac{S_{\text {pellet }} \frac{1}{2}\left(f_{\theta 1}+f_{\theta 2}\right)\left(\Delta u_{\theta 2}-\Delta u_{\theta 1}\right)}{S_{\text {cladding }}}$

where $f_{\theta}$ is the circumferential component of the tangential nodal force at pellet-cladding interface, $\Delta u_{\theta}$ the circumferential component of the tangential displacement discontinuity at pellet-cladding interface (see in Fig. 23), subscripts 1 and 2 refer respectively to the value of a variable at the beginning and at the end of the transient stage, and $S_{\text {pellet }}$ and $S_{\text {cladding }}$ are referential surfaces shown in Fig. 23. This parameter can be approximately considered as an upper bound of the energy density, due to shear loading at pellet-cladding interface, available for the cladding damage process. In this approach it is assumed that the shear energy integrated on $S_{\text {pellet }}$ is available for a through wall crack of a surface $S_{\text {cladding }}$ in the cladding, which mean that $W_{r \theta}$ can be approximately compared to the cladding toughness. Moreover, in Eq. (6), the integration of the shear forces work has been simplified, with the assumption that circumferential friction forces $\left(f_{\theta}\right)$ are linear functions of the tangential displacement discontinuity $\Delta u_{\theta}$, in order to avoid sensitivity of the loading parameter 

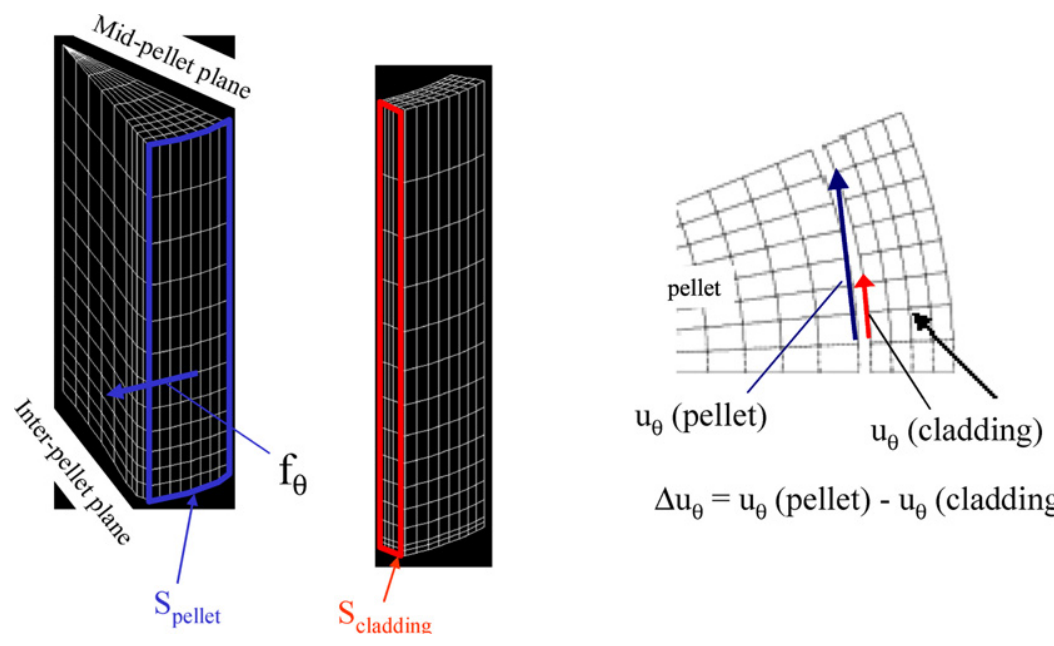

$\Delta \mathrm{u}_{\theta}=\mathrm{u}_{\theta}$ (pellet) $-\mathrm{u}_{\theta}$ (cladding

Fig. 23. Referential surfaces used to compute the circumferential shear energy at pellet-cladding interface.

$W_{r \theta}$ to the number of time steps used to describe the transient stage.

The use of the total energy transmitted at pellet-cladding interface instead of a local shear stress has been motivated by several points:

- an energy parameter seems more adapted to represent the continuous process damage leading to SCC initiation,

- the coulomb friction model can lead to local stress relaxation (due to its unilateral formulation) despite a regular convergence process, then the total shear energy at pellet-cladding interface is less dependent from numerical parameter than the maximal shear stress,

- the strain localisation between two pellet fragments is taken into account in the calculus of the shear energy.

Unfortunately this parameter has also some drawbacks, due to the fact it is less intrinsic, compare to the pellet fragment geometry, than a stress parameter. However this limitation seems acceptable in the framework of phenomenological PCI failure criterion.

The experimental PCI failure curve derived from the power ramp test database, according the two-parameter criterion of Section 5.1, is given in Fig. 24. In this figure, representative loading points of un-failed fuel rods enable us to define a limit loading curve which can considered as a lower bound assessment of the PCI failure curve. The shape of limit loading curve has been defined in order to be conservative if we refer to the conclusions of Section 4.3. In Fig. 24, it is interesting to notice that two-parameter criterion enables to explain the strong impact of the interfacial shear loading and the non-rupture of fuel rods I1 and B1 despite a higher maximum power level during the ramp test (see discussion in previous sections). Then, this phenomenological criterion lead to a unified interpretation of PCI behaviour of fuels rods separated in two zone 1 and zone 2 in Fig. 24.

\subsection{Different type of PCI behaviours}

The analyses of the experimental power ramp test database lead to conclude that there two types of PCI behaviour described by the zone 1 and the zone 2 in Fig. 24. These different behaviours can be characterized by the ratio between the interfacial shear stress loading and the mean circumferential stress in the cladding. The critical power of the ramp test has an inverse proportionality with this ratio for loading points located between the zone 1 and the zone 2 (Fig. 24). This result, discussed through the local stress distribution in the cladding in previous sections, need some further investigation in order to understand the cause of these different PCI behaviours. For this, the cracking strain due to radial cracks in the pellet fragment at the end of the transient stage has been plotted for fuel rods A1 and B1 in Fig. 25. In the latter crack extension in fuel pellets A1 and B1 can schematically described as following:

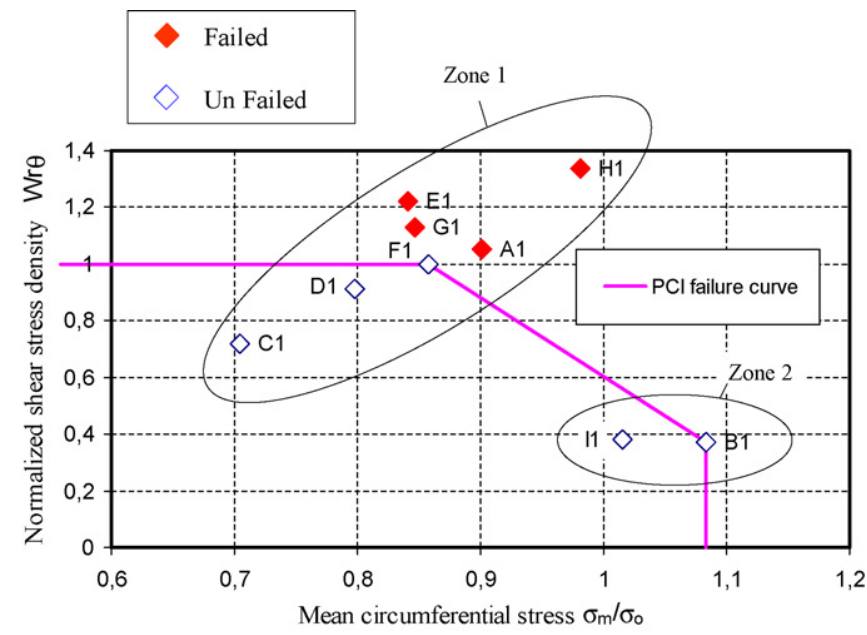

Fig. 24. Experimental PCI failure curve with a two-parameter criterion based on the circumferential shear energy at pellet-cladding interface $\left(W_{r \theta}\right)$ and the mean cladding circumferential stress $\left(\sigma_{\mathrm{m}} / \sigma_{\mathrm{o}}\right)$. 


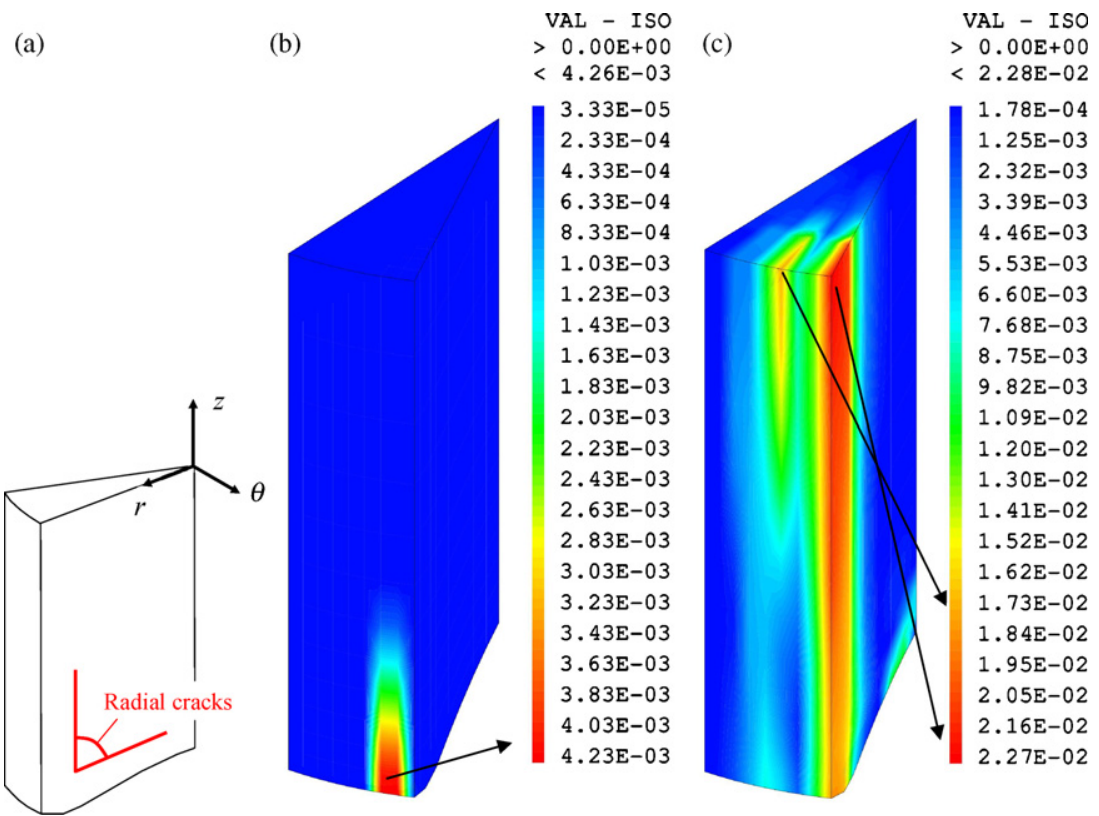

Fig. 25. Cracking strain due to radial cracks at the end of the transient stage: (a) geometrical description of a radial crack, (b) fuel rod A1 and (c) fuel rod B1.

- Fuel rod A1: one small radial crack started at inter-pellet plane in the middle of pellet fragment with a cracking strain level of $0.4 \%$.

- Fuel rod B1: two major radial cracks, one located in the middle of the pellet fragment with a cracking strain level of $2 \%$ between the inter-pellet plane and the mid-pellet plane, and another one located at an intermediate angle, between the middle and the edge of the pellet fragment, with a maximum cracking strain level of $1.8 \%$ in the vicinity of the mid pellet plane.

The link between crack extension level in the pellet fragment and PCI behaviour can be illustrated with the results of Fig. 26 . In the latter, we can see that strain localisation due to crack opening between pellet fragments (Fig. 26a and c) is not greater in the fuel rod B1, although the radius increase during the tran-

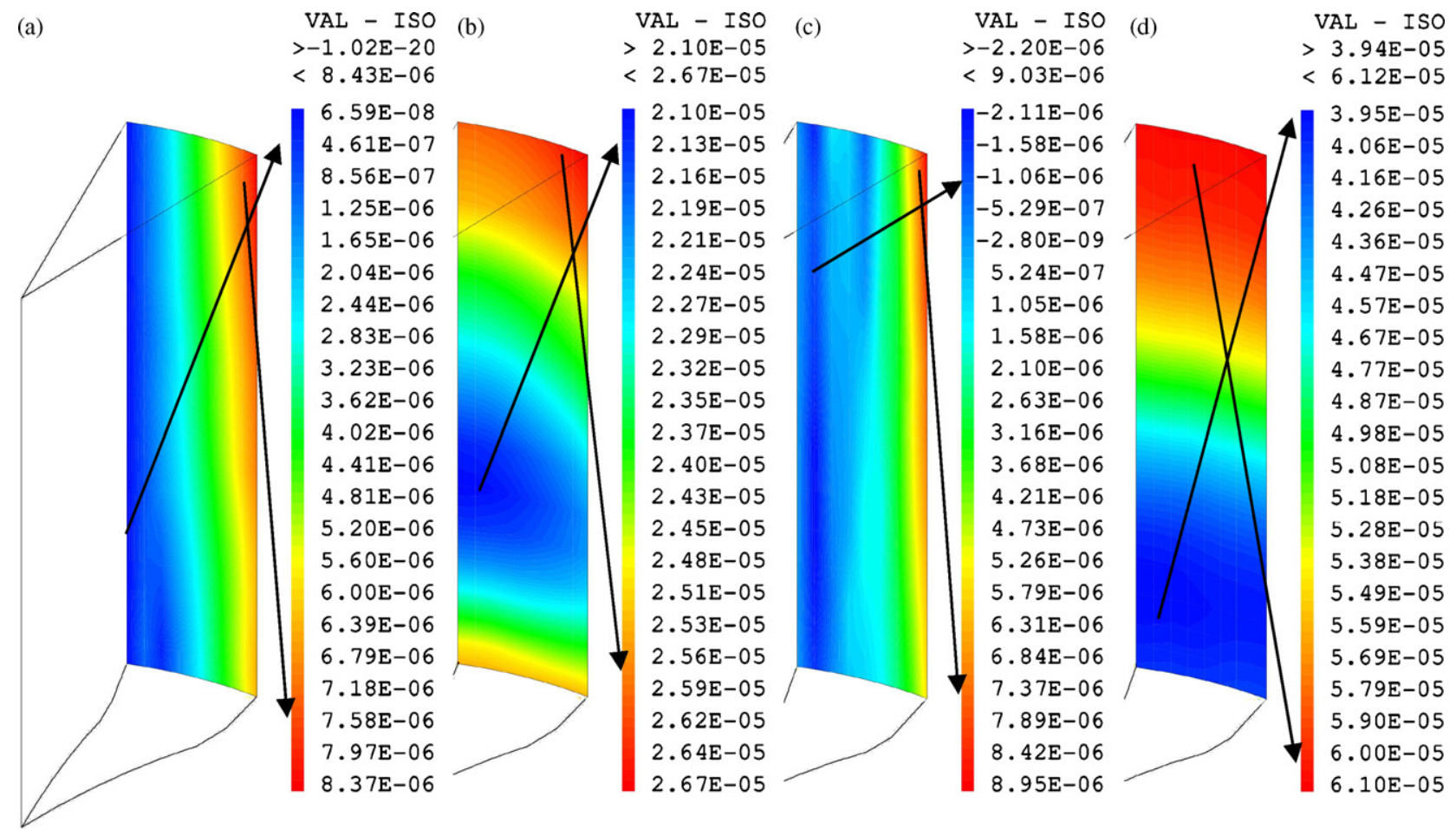

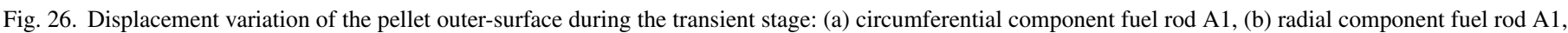
(c) circumferential component fuel rod B1 and (d) radial component fuel rod B1. 

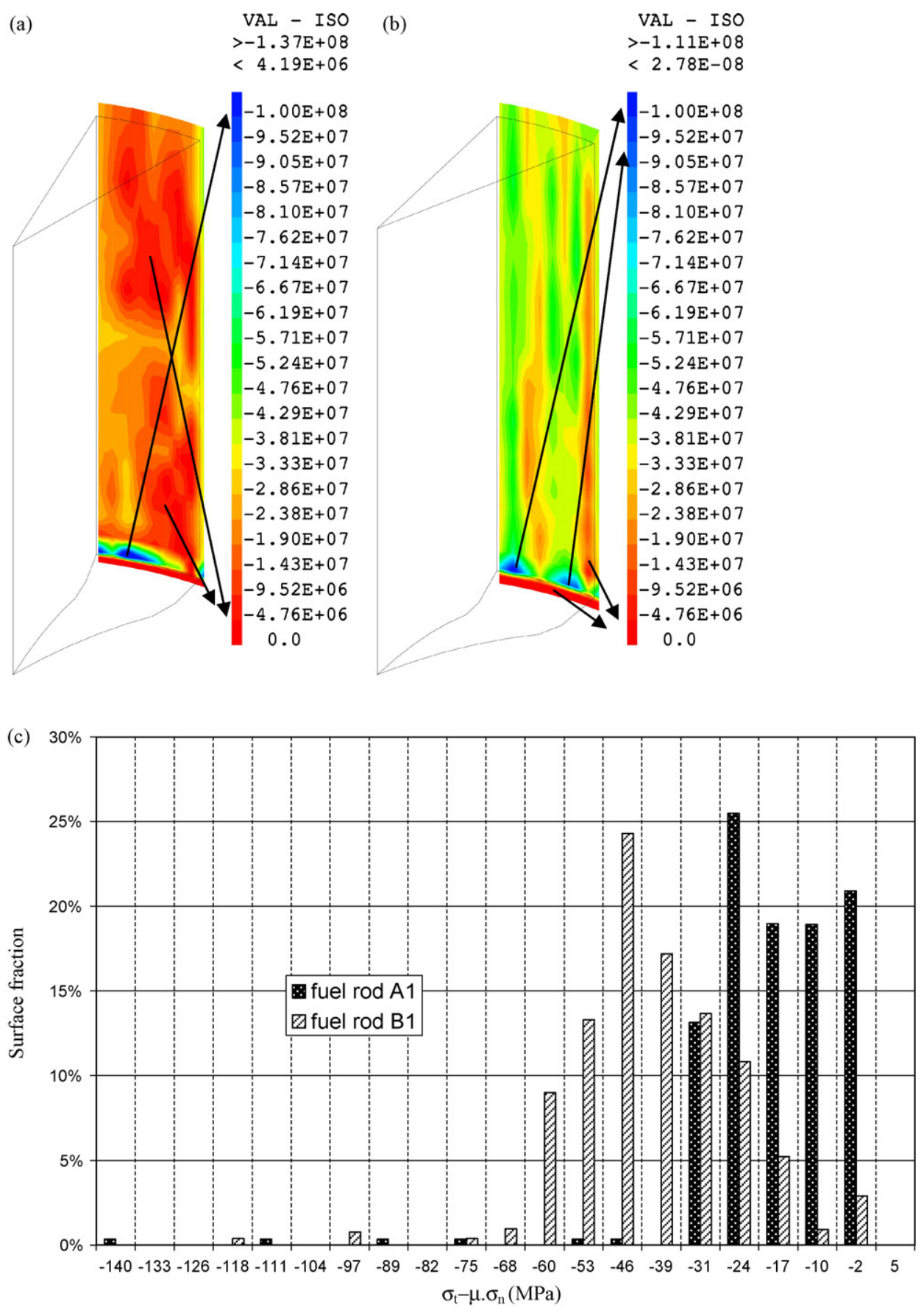

Fig. 27. Distance to the yield sliding stress computed with $\sigma_{\mathrm{t}}-\mu \sigma_{\mathrm{n}}$ at pellet-cladding interface: (a) isovalue for fuel rod A1, (b) isovalue for fuel rod B1 and (c) distribution function of the surface fraction submitted to a stress $\sigma_{\mathrm{t}}-\mu \sigma_{\mathrm{n}}$.

sient stage is almost twice smaller in fuel rod A1 than in fuel rod B1 (Fig. 26b and d). This unexpected result is due to the fact that enhanced opening of radial cracks in fuel rod B1 tends to smooth the displacement discontinuity along the pellet fragment circumference. Then, we can conclude that radial cracks induced by the transient stage inside the pellet fragment lead to a lost of stiffness of the fragment outer part, which explain the threshold effect observed on the interfacial shear stress of fuel rod B1 as shown in Fig. 10. The distance to the sliding stress at pellet-cladding interface, plotted in Fig. 27, confirms that for fuel rod B1 the threshold value of the interfacial stress is smaller then the limit imposed the coulomb friction model. For instance, we can see in Fig. 27 that the distribution function peak is at about $0.09 \sigma_{\mathrm{o}}$ of the sliding stress in fuel rod $\mathrm{B} 1$, whereas the distribution function of fuel rod A1 is more asymmetric with $80 \%$ of the surface where the difference between the interfacial stress and the sliding stress is greater than $-0.05 \sigma_{\mathrm{o}}$.

\section{Conclusions}

A new phenomenological criterion for PCI ruptures has been proposed in this study. After a brief overview of main features 
of the simulation used for fuel behaviour modelling, thermo mechanical aspects of PCI modelling has been detailed with constitutive equations used in the fuel element.

PCI loading during a transient stage of a power ramp test has been discussed through the results of a 3D simulation achieved with the ALCYONE fuel code. It leads to the conclusion that local stresses and strains computed in the cladding of the 3D model could not be used easily to discriminate PCI behaviours observed with experimental results of different types of fuel rods. A new interpretation of the PCI loading has been proposed with the normal and the tangential stresses transmitted at pellet-cladding interface. The distribution of the tangential stress is consistent with PCI crack location observed after destructive examination of failed fuel rods, moreover the maximal value of this tangential stress, also called interfacial shear stress, can be used to defined a unique critical stress for two type of fuel rods made of the same cladding material $(\mathrm{Zy} 4)$.

Two-dimensional computations have then been proposed to estimate the impact of the interfacial shear stress on the stress concentration level in the cladding. This analysis enables us to conclude that the stress concentration level in the vicinity of the cladding inner surface was very sensitive to the interfacial shear stress, which has then a first order effect on the local stress in the cladding. It was also shown that the mesh size in the 3D model was not small enough to assess the stress concentration, which concerns approximately a $30 \mu \mathrm{m}$ zone in the cladding. Based on these results, a phenomenological criterion using the interfacial shear stress and the mean circumferential stress in the cladding was proposed to enable the use of the 3D simulation without changing the mesh refinement. The equivalent PCI loading derived from this two-parameter criterion, is consistent with the local circumferential stress at cladding inner-surface computed with the $2 \mathrm{D}$ model. A set of computations has been used to assess the shape of the equivalent PCI failure curve, which has been build with an isovalue plotting of the local circumferential stress at cladding inner surface. This PCI failure has been used to illustrate the link between the risk of PCI failure and the interfacial shear stress versus the loading path in the global parameter plane. Two kinds of loading paths have been identified on experimental results, which show a significant reduction of the maximal power allowable when the ratio between the interfacial shear stress and the mean circumferential stress increase.

An empirical assessment of the PCI failure has been computed with eight fuel rods extracted from the power ramp test experimental database. In order to avoid numerical dependency the interfacial shear stress parameter has been replaced by the mean shear energy dissipated at pellet-cladding interface during the transient stage. This phenomenological approach enables us to explain the higher PCI critical power level observed for one fuel rod type. Two types of PCI behaviours have been observed, according the different type of loading paths mentioned above. A detailed analysis of the crack density in the pellet external part at the end of the transient stage was used to explain these two types of PCI behaviours. It was shown that an enhancement of the crack density in the pellet external part leads to a loss of stiffness, which reduces the allowable interfacial shear stress at a lower value than the sliding friction threshold.

\section{Acknowledgments}

The present study was supported by the Pellet-Cladding Interaction program co-sponsored between the French Atomic Energy Commission CEA, the Electricité de France EDF and the AREVA-NP. The authors wish to thank all the contributors of this program involved on experimental or simulation aspects linked to this specific study.

\section{References}

Bentejac, F., 2004. TOUTATIS an application of the CAST3M finite element code for PCI three dimensional modelling. In: International seminar on PCI, Aix en Provence, March.

Brochard, J., Bentejac, F., Hourdequin, N., 1997. Non-linear finite element studies of the pellet cladding mechanical interface in PWR fuel. In: Transactions of the 14th SMIRT, Lyon, France (TOUTATIS an application of the CAST3M finite element code for PCI three dimensional modelling).

Contesti, E., 1989. Description of creep-plasticity interaction with non-unified constitutive equations: application to an austenitic stainless steel. Nucl. Eng. Des. 116 (September (II), 3), 265-280.

Garcia, P., Struzik, C., Agard, M., Louche, V., 2002. Mono-dimensional mechanical modelling of fuel rods under normal and off-normal operating conditions. Nucl. Eng. Des. 216 (1-3), 183-201.

Lassmann, K., Blank, H., 1988. Modelling of fuel rod behaviour and recent advances of the TRANSURANUS code. Nucl. Eng. Des. 106, 291-313.

Lassmann, K., Hohlefeld, F., 1987. The revised URGAP model to describe the gap conductance between fuel and cladding. Nucl. Eng. Des. 103, 215-221.

Lucuta, P.G., Matzke, H.S., Hastings, I.J., 1996. A pragmatic approach to modelling thermal conductivity of irradiated $\mathrm{UO}_{2}$ fuel: review and recommendations. J. Nucl. Mater. 232, 166-180.

Michel, B., 2005. PCMI assessment using 3D modelling. In: Transaction of the 18th International Conference SMIRT, Beijing.

Michel, B., Sercombe, J., et al., 2007. 3D fuel cracking modelling in pellet cladding mechanical interaction. Eng. Fract. Mech., doi:10.1016/j.engfractmech.2006.12.014.

Monerie, Y., Gatt, J.M., 2006. Overall viscoplastic behavior of non-irradiated porous nuclear ceramics. Mechanics of Materials 38 (2006), 608-619.

Mougel, C., Verhaeghe, B., Verdeau, C., Lansiart, S., Béguin, S., Julien, B., 2004. Power ramping in the OSIRIS reactor: database analysis for standard $\mathrm{UO}_{2}$ fuel with $\mathrm{Zy}-4$ cladding. In: Pellet-clad Interaction in Water Reactor Fuels, Seminar Proceedings, Aix en Provence, March.

Plancq, D., 2004. PLEIADES: a unified environment for multi-dimensional fuel performance modelling. In: International Meeting on LWR Fuel Performance, Florida.

Roberts, G., 1978. The concentration of stress in cladding produced by the expansion of cracked fuel pellets. Nucl. Eng. Des. 47.

Rousselier, G., Leclercq, S., Diard, O., 2003. Scenario for the damage of PWR fuel cladding in situations of pellet cladding interaction. In: Transaction of the 17th International Conference SMIRT, Prague, Czech Republic, August 17-22.

Soniak, A., L'hullier, N., Mardon, J.P., Rebeyrolle, V., Bouffioux, P., Bernaudat, C., 2002. Irradiation creep behavior of Zr-base alloys. In: Moan, G.D., Rudling, P. (Eds.), Zirconium in the Nuclear Industry: Thirteenth International ASTM STP 1423. ASTM International, West Conshohocken, PA, pp. 837-862.

Struzik, C., Moyne, M., Piron, J.P., 1997. High burn-up modelling of UO2 and MOX fuel with METEOR/TRANSURANUS version 1.5, ANS International Topical Meeting on Light Water Reactor Fuel.

Thouvenin, G., Ricaud, J.M., Michel, B., 2006. ALCYONE: the PLEIADES fuel performance code dedicated to multidimensional PWR studies. In: International Meeting on LWR Fuel Performance, Spain. 